\title{
Behavioral Evidence for Cognitive Dysfunctions in the (BALB/cByJ-Kv1.1mceph/mceph) Mouse Model for Epilepsy
}

\author{
Sarah Holst ${ }^{1,4}$, Elin Åberg ${ }^{2}$, Therese M. Eriksson ${ }^{3}$, Catharina Lavebratt ${ }^{2}$, Sven Ove Ögren ${ }^{1}$ \\ ${ }^{1}$ Department of Neuroscience, Karolinska Institute, Stockholm, Sweden \\ ${ }^{2}$ Department of Molecular Medicine and Surgery, Karolinska University Hospital, Stockholm, Sweden \\ ${ }^{3}$ Center of Molecular Medicine, Department of Physiology and Pharmacology, Karolinska Institute, Stockholm, Sweden \\ ${ }^{4}$ Department of Clinical Neuroscience, Karolinska Institute, Stockholm, Sweden \\ E-mail: Sarah.Holst@ki.se \\ Received July 25, 2011; revised August 16, 2011; accepted September 5, 2011
}

\begin{abstract}
The epileptic mouse model BALB/cByJ-Kv1.1 $1^{\text {mceph/mceph }}$ (mceph/mceph) is homozygous for a spontaneous mutation truncating the Shaker-like voltage gated potassium channel, Kv1.1 (Kcna1). The mceph/mceph mice are asymptomatic at birth, but develop from 3 weeks of age epileptic seizures, overgrowth and neuronal hyperplasia of the hippocampus. Hippocampal cognitive function of the mice was examined by investigating emotional memory using the aversive Passive Avoidance (PA) task combined with studies of explorative behavior using the non-aversive Novel Cage test (NCT). The behavioural results were examined by multivariate analysis. Compared to wild type and heterozygous mice, the mceph/mceph mice displayed lower exploratory and safety assessment behavior in the NCT and impairment in PA retention 24 hours after training, indicating an impairment in cognitive functions. In conclusion, the epileptic mouse model BALB/cByJKv1.1mceph/mceph, with chronic epilepsy related to potassium-channelopathy, display a behavioural phenotype characterized by impairments in emotional memory and defensive motivational responses probably related to hippocampal dysfunctions.
\end{abstract}

Keywords: Epilepsy, Potassium Ion-Channelopathy, Hippocampus, Passive Avoidance, Novel Cage Test, Principal Component Analysis

\section{Introduction}

The potassium-channel subunit Kv1.1 is widely expressed in neurons and forms tetramers with other Kv1 subunits, creating channels that regulate neuronal excitability and signaling. Lack of Kv1.1 has been reported to cause hyperexcitability of CA3 pyramidal cells in hippocampus, of auditory neurons and of pyramidal neurons in the neocortex [1-3]. Consequently, Kv1.1 single amino acid substitutions, currently 17, result in an alteration in channel function, associated with human episodic ataxia type 1 and partial epilepsy in humans [4]. A case study has reported a more severe Kv1.1 mutation that lacked the Cterminal with retained pore domain but altered current kinetics; which was associated with severe drug-resistant episodic ataxia type 1 [5].

The BALB/cByJ-Kv1.1 ${ }^{\text {mceph/mceph }}$ (mceph/mceph) mice carry a spontaneous severe mutation in Kv1.1 resulting in expression of a Kv1.1 containing only the $\mathrm{N}$-terminal domain, the first transmembrane domain and the first extracellular loop. Therefore, this truncated Kv1.1 lacks the voltage sensor and ion pore domains and appears to be rapidly degraded in the brain [6]. Both the $\mathrm{mceph} /$ mceph mice as well as Kv1.1 null mice, which completely lack the Kv1.1, display progressive complex partial seizures involving primarily the limbic system $[7,8]$.

Temporal lobe epilepsy (TLE) is the most common partial epilepsy in adults and there is growing evidence for genetic predisposition [for review see 9]. TLE in humans and rodent models is characterized by hippocampal seizures commonly followed by rapid loss of neural cells through necrosis. Thereafter, there is a dramatic rescue attempt through altered expression of trophic molecules, and an increased gliosis and neurogenesis seen in the hippocampus. The extent of survival of the newly formed cells is controlled by apoptosis [10]. TLE is for some, but far from all, clinical cases accompanied by hippocampal sclerosis (loss of pyramidal neurons, granule cell 
dispersion and reactive gliosis) not directly related to the severity of the epileptic disorder [9].

The mceph/mceph mice show, from 3 weeks of age, mild seizures (hind leg tonus and jittering, epileptiform in vivo EEG recordings and increased firing frequency in stimulated hippocampal mossy cells [7]; Fisahn et al. submitted), disturbances in expression of several growth regulating hormones and trophic neuropeptides in the hippocampus and the amygdala [11], as well as reactive gliosis and increased neuronal proliferation in the hippocampus. The increased proliferation in combination with reduced apoptosis results in a hippocampus characterized by doubled number of neurons in dentate gyrus (DG) and CA3 at 10 - 12 weeks of age [6,12-15]. Kv1.1 null (-/-) mice show a similar phenotype, whereas heterozygous mice (mceph/+ and -/+) show hippocampal volume similar to that in wild types at $10-12$ weeks of age but it is not known if the heterozygotes are characterized by excessive proliferation [13]. Thus, impeding a reduction of intracellular potassium is known to inhibit apoptotic events in various cell types [16].

TLE is often associated with an impaired memory [1719] probably due to hippocampal dysfunctions [20]. The hippocampal formation is crucial for memory, e.g. spatial and emotional memories [21-24]. Thus, specific hippocampal dysfunctions might represent a causal link between seizures and memory impairment [17,25]. Animal models of epilepsy may help to enhance our understanding of mechanisms underlying cognitive abnormalities in different epilepsy disorders. The most common model of TLE, pilocarpine or kainate-induced status epilepticus and subsequent recurrent seizures in rodents, leads to impaired visual-spatial memory and modest neurodegeneration in CA1, CA3 and dentate gyrus [23,24]. In addition, a nonspatial memory deficit was found in the genetic TLE mouse model lacking the presynaptic scaffolding protein Bsn resulting in an abnormal apical dendrite morphology in CA1 pyramidal neurons [26]. Hippocampal related cognitive functions have to our knowledge not been previously investigated in any chronic genetic epilepsy model without hippocampal neurodegeneration.

The aim of the present study was to investigate hippocampal/amygdala [21,29] functions expressed as emotional memory in the Passive Avoidance test (PA) and to relate such effects to the behavioral phenotype in this mouse model of epilepsy by studying homozygous $\mathrm{mceph} /$ mceph mice, and heterozygous (mceph/+) mice. In addition, anxiety-related behavior was assessed in the Elevated Plus Maze (EPM) and Open Field (OF), while the Rotarod was used to investigate motor coordination. The previously described physiological characteristics of mceph/mceph mice, such as teary eyes, low body weight and seizures [27], were scored for verification.
The behaviors displayed at PA training and retention was scored automatically by a computer based system, with the addition of manual recordings of additional behaviors by the experimenter. Moreover, an extensive behavioral characterisation at 3 and 6 weeks of age was performed with the Novel Cage test (NCT). The results obtained in the PA and NCT were analyzed with the multivariate analyse principal component analysis (PCA) in order to characterize a behavioral profiles for each genotype.

\section{Materials and Methods}

\subsection{Animals}

The experiment comprised of 132 BALB/cByJ-Kv1.1 ${ }^{\text {mcephtmceph }}$ (mceph/mceph) mice of wild type $(+/+)$, heterozygotes $($ mceph/+) and homozygous mutants (mceph/mceph) (Experiment 1: wild type $n=10$, heterozygotes $n=22, n=$ 16; Experiment 2: wild type $n=13$, heterozygotes $n=16$, mceph $/$ mceph $\mathrm{n}=9$; Experiment 3: wild type $\mathrm{n}=9$, heterozygotes $n=9$; Experiment 4: heterozygotes $n=18$, mceph $/$ mceph $\mathrm{n}=10$ ). Male and female mice (3 to 6-weeks old) were housed in a light/temperature/humidity-controlled environment: 12-h light-dark cycle (light on at 06:00 h), temperature $22^{\circ} \mathrm{C} \pm 1{ }^{\circ} \mathrm{C}$ and $40 \%-50 \%$ humidity. Mice were housed in groups of 2 - 7 animals in standard transparent M3 Macrolon ${ }^{\circledR}$ cages $(1290 \mathrm{H}$ Euro standard Type III $425 \times 266 \times 155 \mathrm{~mm}$ - floor area $820 \mathrm{~cm}^{2}$, MaterialScience, Leverkusen, Germany) lined with bedding material (Scanbur's Aspen wood Bedding, Scanbur AB Sweden, Sollentuna, Sweden). Food (R34, Labfor, Lantmännen, Stockholm, Sweden) and tap water were provided ad libitum. All experiments were performed between 8 a.m. and 3 p.m. All animals were treated according to the guidelines approved by the local ethics committee (Stockholm Northern Ethics Board of Animal Experimentation) and the "Principles of laboratory animal care" (NIH publication No. 86-23, revised 1985).

\subsection{Experimental Design}

The experimental design was adapted to the brain development and impairments due to seizure activity; the NCT was examined after weaning and one month later to examine developmental impairments. The emotional memory was examined at four weeks when the brain is fully developed [30]. Moreover, this time point was also chosen to avoid the increased seizure activity with age in the mсерh/mceph.

Experiment 1: Each mouse was tested in the NCT after weaning (21 - 22 days of age), PA (four weeks of age) and the NCT (six weeks of age). Body weight, eye condition and vocalisations were recorded after each NCT. Since 
the seizures tend to develop and increase from 3 weeks of age until 6 weeks of age when the animals are retarded, the mice was tested after weaning, in order to test them when they were old enough but not influenced by their seizures and then before they could not perform the NCT test due to too many seizures.

Experiment 2: Each mouse was tested in three tests during their fourth week of age. Two days elapsed between the tests. First they were tested in the PA, followed by $\mathrm{OF}$ and the EPM.

Experiment 3: The motor coordination of two sets of heterozygotes and mceph/mceph mice were examined in the Rotarod. In the first set the mice were 28 and 38 days old and in the second test 28, 34 and 38 days old.

Experiment 4: Five weeks old mice which did not take part in the behavioral experiments were used for the histological examination. This procedure was used in order to reduce the risk of eliciting seizure in mice subjected to the behavioural testing.

\subsection{Step-Through Passive Avoidance Test (PA)}

The PA emotional memory task was chosen since pilot studies showed large variations in the ability to perform the tasks in two other memory tests; Novel Object Recognition test and the Morris Water Mazes related to a high degree of emotionality in the background strain BALB/c [28].

The PA task is an associative learning paradigm based on contextual fear conditioning (Pavlovian conditioning), involving neuronal circuits in the limbic forebrain, such as hippocampus and amygdala [21,29]. In the step-through PA procedure, performed in a two-compartment box, the suppression of the innate preference of rodents for the dark compartment following the exposure to an inescapable foot shock is defined as PA behavior [29-32]. Memory retention was tested in a computer-controlled PA (TSE-Systems GmbH, Homburg, Germany). In order to evaluate the effect of strength of the aversive cue on performance two separate experiments was performed; the first experiment had an electrical current of $0.30 \mathrm{~mA}$ and the second of $0.50 \mathrm{~mA}$.

Test of memory retention was performed 24 hours after the training [31,32]. During training the mouse was placed in a brightly lit (ca 1200 lux) compartment (BC) $(280 \times$ $155 \times 160 \mathrm{~mm}$ ) for $60 \mathrm{~s}$. Then the door between the compartments was opened and the mouse has free access to the dark compartment (DC) $(280 \times 155 \times 160 \mathrm{~mm})$. Upon entering the DC the door closes after $3 \mathrm{~s}$ and the mouse received weak electrical current (US) (duration $1 \mathrm{~s}$ ) 0.30 $\mathrm{mA}$ (Exp. 1, "low aversity") or 0.50mA (Exp. 2, "high aversity"). The mouse is left in the dark compartment for $60 \mathrm{~s}$ after the aversive cue (US) had been presented to increase the association of the context and the US [31,32].
In the retention test the mouse was placed in the $\mathrm{BC}$ with the door closed. After $15 \mathrm{~s}$ the door was opened and the mouse had free access to both compartments for $10 \mathrm{~min}$, $600 \mathrm{~s}$. The memory retention was examined by measuring the latency time to the first transfer from the $\mathrm{BC}$ to the DC with a cut-off latency of $10 \mathrm{~min}$ (600 s) [31-33]. After the end of each test, the arena was cleaned and deodorised after each animal using 70\% ethanol.

Since the mceph/mceph mice have a reduced locomotor activity partly due to sub-epileptic seizures, to facilitate step-through the size of the $\mathrm{BC}$ was diminished to one third of the total size, by placing a wall of transparent plastic placed 10 grid bars away from the door.

In addition to the step-through latency time, the duration of activity, inactivity, exploration, place preference and transfers were computer based calculated by the PA software (see Table 1 for definitions). Moreover, the frequency of rearings (free- and wall rearing), stretch attend postures (SAP) and grooming, as well as the number of feces were recorded manually (see Table 1 for definitions).

\subsection{Novel Cage Test (NCT)}

The NCT evaluates emotional reactivity by quantifying exploration and risk assessment behavior [34]. The mouse was placed in the centre of clean a Macrolon type III cage with fresh bedding under a light intensity of approximately 200 lux. The behavior was video-recorded for $5 \mathrm{~min}$ using a digital camera placed above the cage. The latency time, frequency and duration of the behaviors described in Table 2. were analyzed with EthoLog ${ }^{\circledR}$ [35].

After NCT the mice were weighed (SP401 Scout Pro Scale, Ohaus Corporation ${ }^{\circledR}$, New Jersey, USA). Since the mсерh/mceph mice often have red and teary eyes the eye condition of the individual was registered as normal (0) or abnormal (1). In addition, the number of vocalisations per individual was registered during handling by the experimenter.

\subsection{Elevated Plus Maze (EPM)}

Anxiety-related behavior was assessed using the EPM consisting of a cross-shaped platform with two arms without walls (open arms; $30 \times 5 \mathrm{~cm}$ ), two arms with walls (closed arms; $30 \times 5 \mathrm{~cm}$ ) with open endings and a central arena $(5 \times 5 \mathrm{~cm})$. The apparatus was elevated $1 \mathrm{~m}$ above the floor. The light intensity on the EPM was about 300 lux. Two white lamps placed above and facing outwards, as well as a fluorescent lamp illuminated the arena indirectly. Mice were placed individually in the central arena and left to explore for $5 \mathrm{~min}$. The latency time to first visit, the total visits, distance travelled and time spent in the open arms, closed arms and in the central region were 
Table 1. Ethogram of behaviors registered in the PA test (Exp 1 \& 2).

\begin{tabular}{|c|c|c|c|c|}
\hline \multicolumn{2}{|c|}{ Behavioral categories (unit) } & \multirow{2}{*}{$\begin{array}{l}\text { Computer based (C) } \\
\text { or visually recorded } \\
\qquad(\mathrm{V}) \\
\mathrm{C}\end{array}$} & \multirow{2}{*}{$\begin{array}{c}\text { Measured in BC and/or } \\
\text { DC during Training (TR) } \\
\text { and/or Retention (RE) } \\
\text { TR/RE BC DC }\end{array}$} & \multirow{2}{*}{$\begin{array}{l}\text { Definition } \\
\text { or activity more than } 5 \mathrm{~cm} / \mathrm{s} \text { in BC }\end{array}$} \\
\hline$I$ & Activity (s) & & & \\
\hline & Inactivity (s) & $\mathrm{C}$ & TR/RE BC DC & $\begin{array}{l}\text { Duration of no activity less than } 5 \mathrm{~cm} / \mathrm{s} \text { measured in } \\
\text { BC during training before door opened. }\end{array}$ \\
\hline \multirow[b]{2}{*}{ Exploration } & Exploring (s) & $\mathrm{C}$ & TR/RE BC DC & $\begin{array}{l}\text { Forward locomotor activity in which two photo beams } \\
\text { after one another is broken in BC respective DC. }\end{array}$ \\
\hline & Free rearing (nr) & $\mathrm{V}$ & TR BC RE & $\begin{array}{l}\text { Rising and standing only on hind legs and then putting } \\
\text { the front legs back down. }\end{array}$ \\
\hline \multirow[t]{2}{*}{ Risk assessment } & $\begin{array}{l}\text { Stretched attend } \\
\text { posture (SAP) (nr) }\end{array}$ & $\mathrm{V}$ & RE BC & $\begin{array}{l}\text { Stretching the neck or front part of the body while } \\
\text { sniffing the air, with } 4 \text { paws on the floor. Measured } \\
\text { only at the retention session. }\end{array}$ \\
\hline & Grooming (nr) & $\mathrm{V}$ & TR/RE BC & $\begin{array}{l}\text { Shaking, scratching, wiping or licking body parts (fur, } \\
\text { ears, nose, tail). }\end{array}$ \\
\hline \multirow{3}{*}{ Other } & Time spent in BC (s) & $\mathrm{C}$ & RE BC DC & The duration of photo beams broken in the BC. \\
\hline & Time spent in DC (s) & $\mathrm{C}$ & RE BC DC & The duration of photo beams broken in the DC. \\
\hline & Feces (nr) & $\mathrm{V}$ & TR/RE BC DC & Number of feces in BC/DC. \\
\hline
\end{tabular}

Table 2. Ethogram of behaviors registered in NCT (Exp 1).

\begin{tabular}{|c|c|c|}
\hline \multicolumn{2}{|c|}{ Behavioral categories } & \multirow[t]{2}{*}{ Definition } \\
\hline \multirow{2}{*}{ Locomotion } & Motionless & \\
\hline & Walking & Locomotor behavior with normal body posture. \\
\hline \multirow[t]{2}{*}{ Exploration } & Free rearing & Standing on hind legs. \\
\hline & Wall rearing & Standing on hind legs with forepaws leaning against a wall. \\
\hline \multirow[t]{2}{*}{ Risk assessment } & $\begin{array}{l}\text { Stretch attend } \\
\text { posture (SAP) }\end{array}$ & $\begin{array}{l}\text { Stretching the neck or front part of the body while sniffing the air, with } 4 \text { paws on the floor a flat body } \\
\text { posture. }\end{array}$ \\
\hline & Stretch approach & Walking with a flat body posture stretched and close to the floor. \\
\hline \multirow{4}{*}{ Other behaviors } & Self-Grooming & Displacement behavior; Scratching, shaking, wiping or licking body parts (fur, ears, nose, tail). \\
\hline & Burrowing & Defensive behavior; Moving substrate forward with front paws and nose, or backwards with hind paws. \\
\hline & Freezing & Escape behavior; Sudden suppression of movement. \\
\hline & Escape & Jumping towards the walls of the apparatus-measured but did not appear. \\
\hline
\end{tabular}


recorded by a video camera mounted in the ceiling and analysed by the TSE system (Hamburg, Germany), as well as the number of transitions between the walled arms. Arm entries were defined as entering the arms with all four paws. The open time ratio is taken as a measure of anxiety-like behavior and is calculated by dividing the time spent in the open arms and the central region with the total time. After the end of each test, the arena was cleaned as described in the PA.

\subsection{Open Field Test (OF)}

Spontaneous locomotor activity and anxiety-like behavior were assessed in an OF chamber, a square arena $(50 \times$ $50 \times 25 \mathrm{~cm}$ ) made of black glacial polyvinyl chloride. Intense light and sound often provokes seizures in the mceph/mceph mice, so the arena was sparsely illuminated by $2 \times 60 \mathrm{~W}$ lamps with red light mounted $1.5 \mathrm{~m}$ above the box. The area was divided into 16 quadrants (4 central and 12 peripheral, $10 \mathrm{~cm}$ from the walls). Mice were placed individually into the centre of the OF and left to explore for $5 \mathrm{~min}$. The time spent in the central and peripheral zones, total distance travelled during the experiment and numbers of crossings between the zones were automatically recorded by the TSE digital analysing system based on a video camera and PC-compatible software (TSE, Hamburg, Germany). To assess anxiety-like behavior, the percentage of the time spent in the centre of the OF was used. The box was cleaned as described in the PA.

\subsection{Accelerating Rotating Rod Test}

The accelerating Rotarod (Ugo Basile, Biological Research Apparatus, Varese, Italy) was used to test balance and motor coordination. The Rotarod test was performed by placing a mouse on a rotating drum (3 $\mathrm{cm}$ of diameter) and automatically recording the time that each mouse was able to achieve walking on the top of the rod. The speed of the Rotarod accelerated from 8 to $40 \mathrm{rpm}$ over a 4.5-min period. Mice were given four consecutive trials with a minimum of 15 min inter-trial rest interval. The fall latency average of these four trials was used for statistical analysis.

\subsection{Perfusion}

Mice deeply anesthetised with isofluran (Abbot Scandinavia $A B$, Solna) were perfused transcardially with 10 $\mathrm{ml} \mathrm{Ca}{ }^{2}$-free Tyrode's solution including $0.1 \mathrm{ml}$ heparin, followed by $50 \mathrm{ml}$ of fixative (4\% paraformaldehyde and $0.4 \%$ picric acid in 0.16 M PBS, $\mathrm{pH} 7.4$ ) at forced pressure. Brains were dissected and postfixed in the same fixative for $1 \mathrm{~h}$ at room temperature and subsequently rinsed in $0.1 \mathrm{M}$ PBS with $10 \%$ sucrose and $0.1 \%$ sodium azide several times during $48 \mathrm{hr}$. The brains were stored in sucrose solution at $4^{\circ} \mathrm{C}$ before cryosectioning.

\subsection{Immunohistochemistry}

Coronal sections $30 \mu \mathrm{m}$ were cut using a cryostat (Microm) through the entire hippocampus starting at $-0.94 \mathrm{~mm}$ from bregma and ending at $-3.88 \mathrm{~mm}$ from bregma [36].

Every tenth section was processed for mature neuronal nuclei, by staining with NeuN (Chemicon, Temicula, CA, USA) immunohistochemistry. A mouse on mouse (MOM) kit for NeuN-immunodetection (Vector, Burlingame, CA, USA) was used according to manufacturer's instruction. Briefly, primary antibody (NeuN, 1:100) was diluted in MOM diluent and incubated in $4^{\circ} \mathrm{C}$ overnight. Biotinylated secondary antibody (antimouse IgG, MOM kit) was diluted in MOM diluent (1:250) followed by an incubation in room temperature for $1 \mathrm{~h}$. Avidin-biotin (Vector Laboratories, Inc. Burlingame, CA, USA) was then administered for $40 \mathrm{~min}$ in room temperature followed by visualization by 3.3'-diaminobenzidine (DAB) (SigmaAldrich Sweden AB, Stockholm, Sweden). All slides were dehydrated and mounted with Pertex (Histolab Products AB, Göteberg).

\subsection{Stereology}

The optical fractionators-method was used to count NeuNimmunoreactive cells in the entire dentate gyrus [36-38]. Briefly, every tenth section was systematically sampled and an unbiased counting frame with a known area was then superimposed on the field of view, where after counting frames were systematically distributed throughout the marked region from a random starting point. The optical fractionator estimates are free of assumptions about cellular shape and size and are unaffected by tissue shrinkage. The dentate gyrus, including an area exceeding the subgranular zone by two cell diameters and an area exceeding the molecular layer by one cell diameter, was manually outlined using a $10 \times$ lens. Cell counts were performed with a $60 \times$ lens (numerical aperture $=1.4$ ).

\subsection{Statistical Analysis}

The data were first analysed for the normality by assessing the sample distribution or by Levine's test of homogeneity for variances. The results which passed the tests for normality were analysed with parametric test. Differences between the groups were tested with one wayanalysis of variance (ANOVA). Significant differences between groups were tested with the Fisher LSD test. The results which did not passed the tests for normality 
were analysed with the non-parametric Mann Whitney-U test. Comparisons of repeated measurements were analysed by the Wilcoxon Matched Pairs Test; p-values of 0.05 or less were regarded as statistically significant. The results were analysed using Statistica ${ }^{\circledR} 7.0$ (Statsoft, Uppsala, Sweden). The results analysed parametrically are presented as means \pm SEM. The results analysed non-parametrically are presented as scatter plot with median.

A pattern recognition analysis was used to establish the different response patterns of each genotype by use of a multivariate data analysis, the SIMCA (Soft Independent Modelling of Class Analogy), principal components analysis (PCA); PCA SIMCA-P+11 software (Umetrics $\left.{ }^{\circledR}\right)$. Using both scaling and mean-centring, variables are pre-processed to standardise weighting of each parameter. The PCA transforms the number of possibly correlated variables into a smaller number of uncorrelated variables that are called principal components. The first component represents the largest variation in the data set, the second component the largest of the remaining variance, etc [39].

\section{Results}

\subsection{Step-Through Passive Avoidance}

\subsubsection{Step-Through Latency}

Low aversity cue (Exp 1)

There was a significant effect of genotype on training latency $(\mathrm{H}(2, \mathrm{~N}=39)=10.72$, $\mathrm{p}=0.0046)$, as well as on the retention latency $(\mathrm{H}(2, \mathrm{~N}=47)=6.46, \mathrm{p}=0.040)$ (Figure 1, Table 3).
High aversity cue (Exp 2)

The training latency was longer in the mceph/mceph mice $(\mathrm{H}(2, \mathrm{~N}=50)=8.01, \mathrm{p}=0.018)$, compared to the heterozygous ( $p=0.0046)$ and to the wild types $(p=0.014)$. There was no significant effect of genotype on the retention latency (Figure 1, Table 3).

Comparing the training latency time with the retention latency within the same individual showed in both experiments, that the retention latency was significantly increased in the wild type $(Z=2.38, p=0.017 ; Z=2.84$, $p$ $=0.0045)$ and heterozygotes $(Z=3.12, p=0.0018 ; \mathrm{Z}=$ $3.88, \mathrm{p}=0.00011$ ) whereas it was unchanged in the mceph/mсерh mice $(\mathrm{Z}=0.45, \mathrm{p}=0.65 ; \mathrm{Z}=1.18$, $\mathrm{p}=0.24$ ) (Figure 1, Table 3 ). These data indicate that the wild type and heterozygous mice acquired the emotional learning task, since they showed avoidance of the aversive dark compartment, at retention. In contrast, latency between training and retention did not differ in the $m$ ceph/mceph mice.

\subsubsection{Additional Behaviors Recorded in the PA}

Compared to wild type and the heterozygous mice the mceph/mceph mice, in both experiments, displayed a significantly lower risk assessment and explorative behaviors, as well as general activity in the bright compartment (Table 3).

\subsubsection{Comparison of the mceph/mceph, Heterozygous and Wild Type Mice in the PA}

In view on the large amount of data recorded during the $\mathrm{PA}$, it is critical to use statistics that include multivariate analysis. Therefore, PCA based on the PA results presented in the Table $\mathbf{3}$ was used to identify clusters and

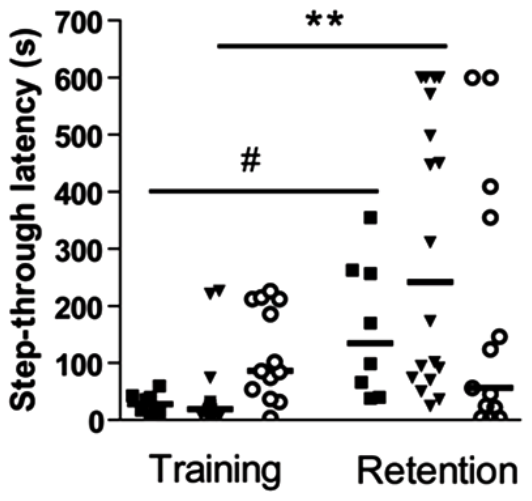

(a)

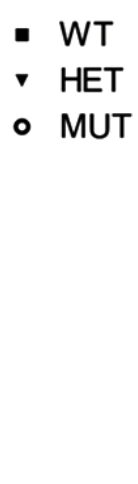

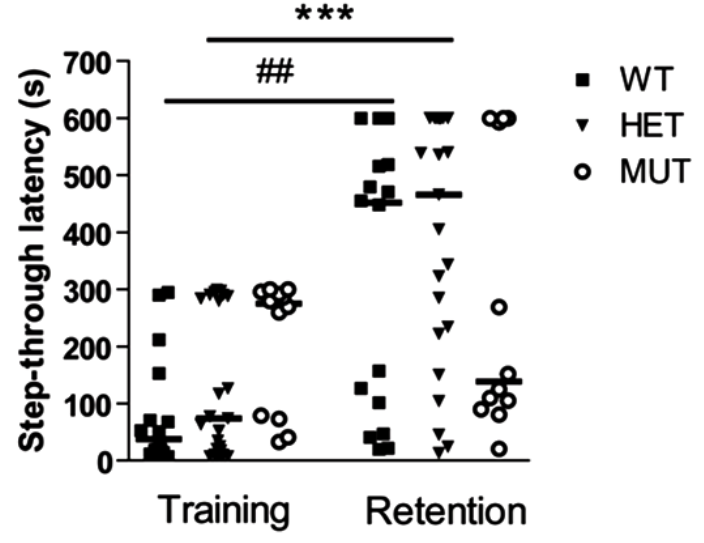

(b)

Figure 1. The step-through latency time (s) of "low adversity" (Exp. 1, 0.30 mA) (a) and "high aversity" (Exp. 2, 0.50 mA) (b) in the Passive Avoidance (PA) test presented in a scatter plot with median. The retention latency was significantly increased compared to the training latency in the wild type $(0.30 \mathrm{~mA}: \mathrm{p}<0.05 ; 0.50 \mathrm{~mA}: \mathrm{p}<0.01)$ and heterozygous $(0.30 \mathrm{~mA}$ : $\mathrm{p}<0.01$; $0.50 \mathrm{~mA}: \mathrm{p}<0.001$ ), while it was unchanged in the mceph $/$ mceph mice. WT $=$ wild type mice, HE = to heterozygous mice, MUT $=$ mceph $/$ mceph mice. \# $\mathbf{p}=0.05 \#$ \# $=0.01$ comparing training to retention in wild type mice, ${ }^{* *} p=0.01 ; * * * p=0.001$ comparing training to retention in heterozygous mice. 
Table 3. Behavioral data from the PA test.

\begin{tabular}{|c|c|c|c|c|c|c|c|}
\hline \multirow{2}{*}{$\begin{array}{l}\text { Behavioral } \\
\text { categories }\end{array}$} & \multirow{2}{*}{ Behavior } & \multicolumn{3}{|c|}{ Low aversity cue } & \multicolumn{3}{|c|}{ High aversity cue } \\
\hline & & wt & $\mathrm{h}$ & $\mathrm{m}$ & wt & $\mathrm{h}$ & $\mathrm{m}$ \\
\hline \multirow{5}{*}{ General Activity } & TR BC InAct & 4.9 (2.2 to 13.3$)$ & 9.9 (0 to 78.6$)$ & $\begin{array}{c}61.4(22.7 \text { to } 86.3) \\
* * *\end{array}$ & $8.0(0$ to 77$)$ & 13.0 (2 to 59$)$ & 32.5 (5 to 70$)$ \\
\hline & TR Act cue & 55.2 (15.9 to 85.1) & 72.3 (23 to 126.6 ) & 61.6 (52.8 to 78.8 ) & 66.5 (40 to 82 ) & 61.5 (39 to 89) & 64.5 (5 to 88$)$ \\
\hline & TR Act delay & 19.2 (17.6 to 23.5$)$ & $\begin{array}{c}18.7(010.1 \text { to } \\
24.3)\end{array}$ & 23.6 (10.7 to 30.9) & 15.5 (4 to 22$)$ & 15.5 (7 to 24$)$ & 18.5 (13 to 22$)$ \\
\hline & RE BC Act & 4.6 (3.3 to 7.1 ) & $2.8(1.7$ to 7.0$)$ & $\begin{array}{c}0.8(0.1 \text { to } 3.6) \\
* * *\end{array}$ & $4.0(2.0$ to 7.0$)$ & 3.5 (0 to 6$)$ & $1(0$ to 2$) * * *$ \\
\hline & RE DC Act & $3.9(0.2$ to 7.1$)$ & 3.4 (0 to 10$)$ & 8.5 (0 to 22.9$)$ & 1.0 (0 to 7$)$ & $2.0(0$ to 10$)$ & 4.0 (0 to 8$)$ \\
\hline \multirow{6}{*}{ Exploration } & TR Rearing & 3.0 (0 to 8$)$ & 0.0 (0 to 5$)$ & 0.0 (0 to 4$)$ & $1.0(0$ to 5$)$ & 0.0 (0 to 3$)$ & $0.0(0 \text { to } 1)^{* *}$ \\
\hline & RE BC Expl & 31.4 (27.1 to 32.9) & 30.0 (15.7 to 32.1$)$ & 9.3 (3.6 to 30 ) *** & 30.0 (17 to 34$)$ & 30 (4 to 32$)$ & $\begin{array}{c}8.0(2.0 \text { to } 22.0) \\
* * *\end{array}$ \\
\hline & RE DC Expl & 75.7 (5.7 to 78.6 ) & 63.6 (0 to 78.6$)$ & 53.6 (0 to 78.6$)$ & 31.0 (8 to 77$)$ & 65.5 (0 to 77$)$ & $37.0(0$ to 71$)$ \\
\hline & RE Re bef & $0.0(0$ to 2$)$ & $0.0(0$ to 5$)$ & $0.0(0$ to 11$)$ & 0.0 (0 to 5$)$ & 0.0 (0 to 7$)$ & $0.0(0$ to 0$)$ \\
\hline & RE Re aft & $3.0(0$ to 5$)$ & 0.5 (0 to 5$)$ & 1.0 (0 to 7$)$ & 1.0 (0 to 26$)$ & 1.0 (0 to 8$)$ & 0.0 (0 to 14$)$ \\
\hline & RE Transfers & 14.5 (4 to 27 ) & $3.0(0$ to 31$)$ & 1.0 (1 to 7$)^{* * *}$ & 2.5 (0 to 32 ) & $3.5(0$ to 11$)$ & 1 (0 to 4$)$ \\
\hline \multirow{2}{*}{ Risk assessment } & RE SAP bef & 2.0 (1 to 16$)$ & 5.0 (0 to 25$)$ & $0.0(0$ to 2$) * *$ & 5.5 (0 to 14$)$ & 6.5 (0 to 26$)$ & $0.5(0$ to 8$) * *$ \\
\hline & RE SAP aft & 4.0 (1 to 16$)$ & 4.5 (0 to 28$)$ & $0.0(0$ to 14$) * *$ & $1.0(0$ to 15$)$ & 0.0 (0 to 3$)$ & 0.0 (0 to 1$)$ \\
\hline \multirow{3}{*}{$\begin{array}{c}\text { Displacement } \\
\text { behaviors }\end{array}$} & TR Groo & $0.0(0$ to 1$)$ & $0.0(0$ to 2$)$ & $0.2(0$ to 2$)$ & $0.0(0$ to 2$)$ & $1.0(0$ to 2$)$ & $0.0(0$ to 2$)$ \\
\hline & RE Groo bef & $1.0(0$ to 4$)$ & $1.0(0$ to 8$)$ & $0.0(0$ to 4$)$ & $2.0(0$ to 6$)$ & 2.5 (0 to 8$)$ & 0.0 (0 to 5$)$ \\
\hline & RE Groo aft & 2.5 (0 to 5$)$ & $2.0(0$ to 6$)$ & $2.0(0$ to 3$)$ & $2.0(0$ to 7$)$ & $2.0(0$ to 5$)$ & $3.0(0$ to 4$)$ \\
\hline \multirow{2}{*}{ Open-shelter } & RE Pl BC & 444.6 (214 to 593 ) & 488.0 (80 to 600$)$ & 74.3 (2 to 600$)$ & 531.7 (189 to 594) & 533.8 (47 to 600 ) & 148.8 (82 to 600$)$ \\
\hline & RE Pl DC & 155.4 (7 to 386$)$ & $112.0(0$ to 520$)$ & 525.7 (0 to 598$)$ & 68.3 (6 to 411$)$ & 160 (0 to 553$)$ & 451.2 (0 to 518$)$ \\
\hline \multirow{4}{*}{$\begin{array}{l}\text { Anxiety-related } \\
\text { behavior (Feces) }\end{array}$} & TR BC Fe & $2.0(0$ to 4$)$ & $2.0(0$ to 5$)$ & $1.0(0$ to 6$)$ & $2(0$ to 5$)$ & $3(0$ to 10$)$ & 1 (0 to 2$)$ \\
\hline & RE BC Fe bef & $1.5(0$ to 6$)$ & $4.0(0$ to 11$)$ & $1.0(0$ to 4$)$ & $3(0$ to 10$)$ & $4(0$ to 8$)$ & 2 (0 to 8$)$ \\
\hline & RE BC Fe aft & $2.0(0$ to 5$)$ & $1.0(0$ to 4$)$ & $0.0(0 \text { to } 1)^{* *}$ & $0(0$ to 4$)$ & 0 (0 to 2$)$ & 0 (0 to 5$)$ \\
\hline & RE DC Fe & 0.0 (0 to 5$)$ & 0.0 (0 to 8$)$ & 1.5 (0 to 6$)$ & $0(0$ to 4$)$ & 0 (0 to 6$)$ & 2 (0 to 4 ) \\
\hline
\end{tabular}

Table is showing results from the Passive Avoidance test. Data is presented as medians $($ minimum to maximum) $*=\mathrm{p}=0.05, * *=\mathrm{p}=0.01, * * *=\mathrm{p}=0.001$ compared to wt who received the same aversive cue. Abbreviations: TR $=$ Training day, RE $=$ Retention day, BC $=$ Bright Compartment, DC $=$ Dark Compartment, Lat = Latency time to step-through; InAct = InActivity before the door is opened.; Act Cue = Activity during aversive cue.; Act delay = Activity during delay after aversive cue.; Act = Activity after the door is opened,; Expl = Exploring after the door is opened.; Re = the number of rearings; bef = before step-through.; aft = after step-through.; SAP = the number of stretch attend postures; Gro = the number of self groomings; Trans = the number of transfers after the door opened.; $\mathrm{Pl}=$ Place preference (the total duration in a region after the door opened); $\mathrm{Fe}=$ the number of feces pellets, wt $=$ wild type, $\mathrm{h}=\mathrm{heterozygotes,}$ $\mathrm{m}=$ mсерh/mсерh. Modified after [28,40].

correlations of behavioral patterns related to the genotype of the mice. Figures 2(a) and (c) shows the scoring plot with the distribution of the individuals related to variables, and Figures 2(b) and (d) shows the loading plot with the variables distributed related to their correlations. Variables located in the same quadrant of the PCA-plot are positively correlated to one another. Variables located in opposite quadrants are negatively correlated to one another. The distance of the variable from the origo is related to the deviation from the average. The ellipse describes two standard deviations from the origo, individuals found outside the ellipse are considered outlayers. 


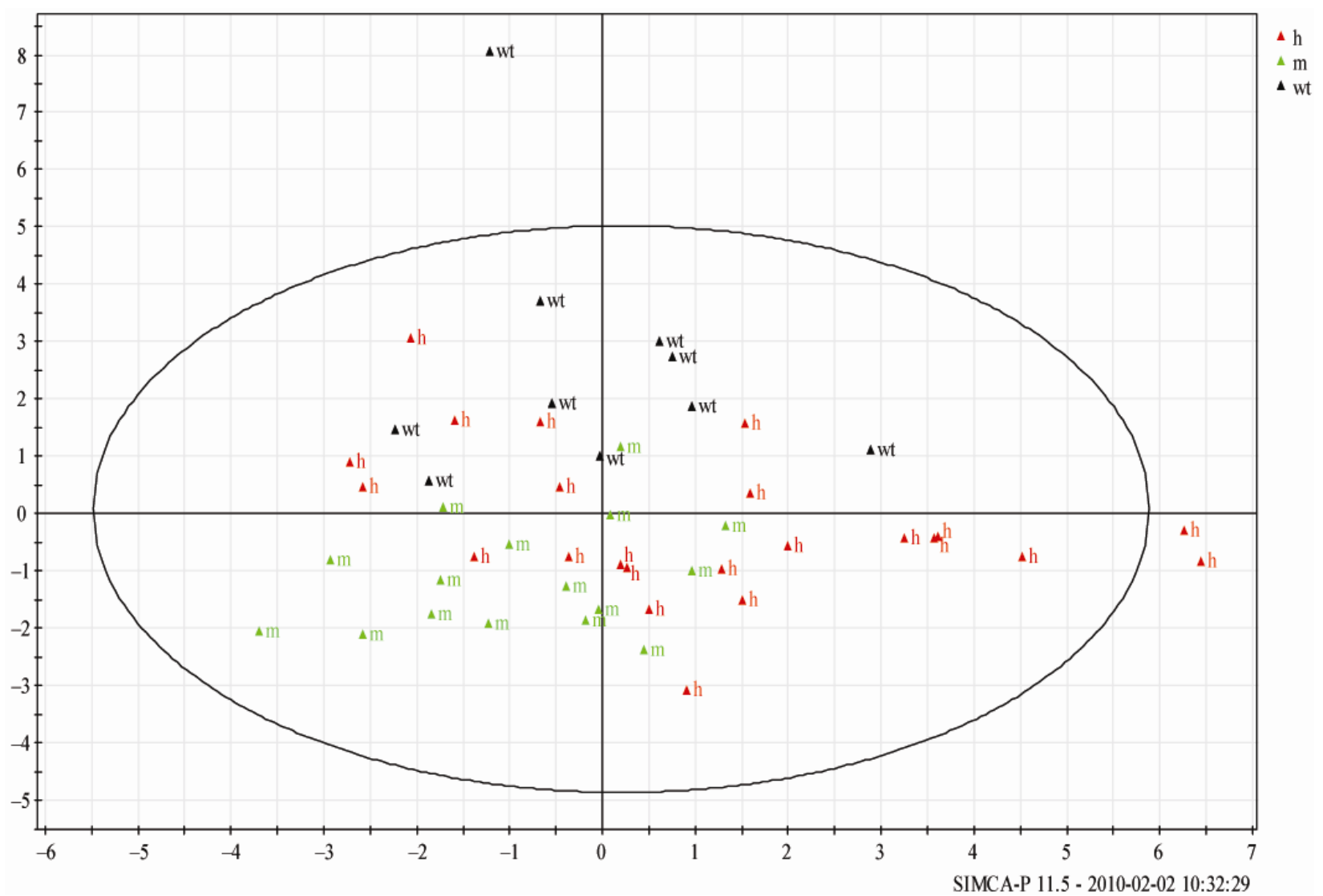

(a)

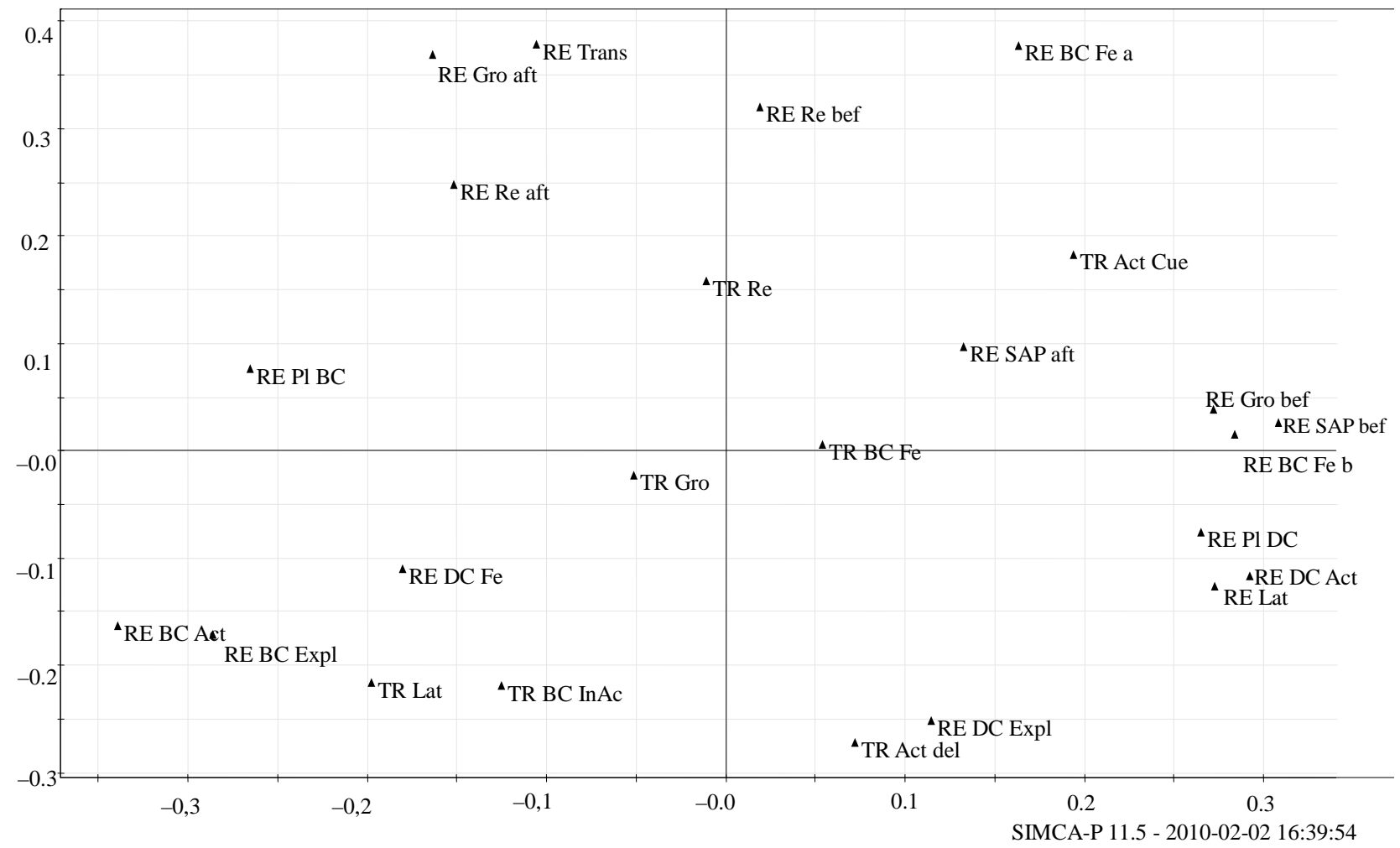

(b) 


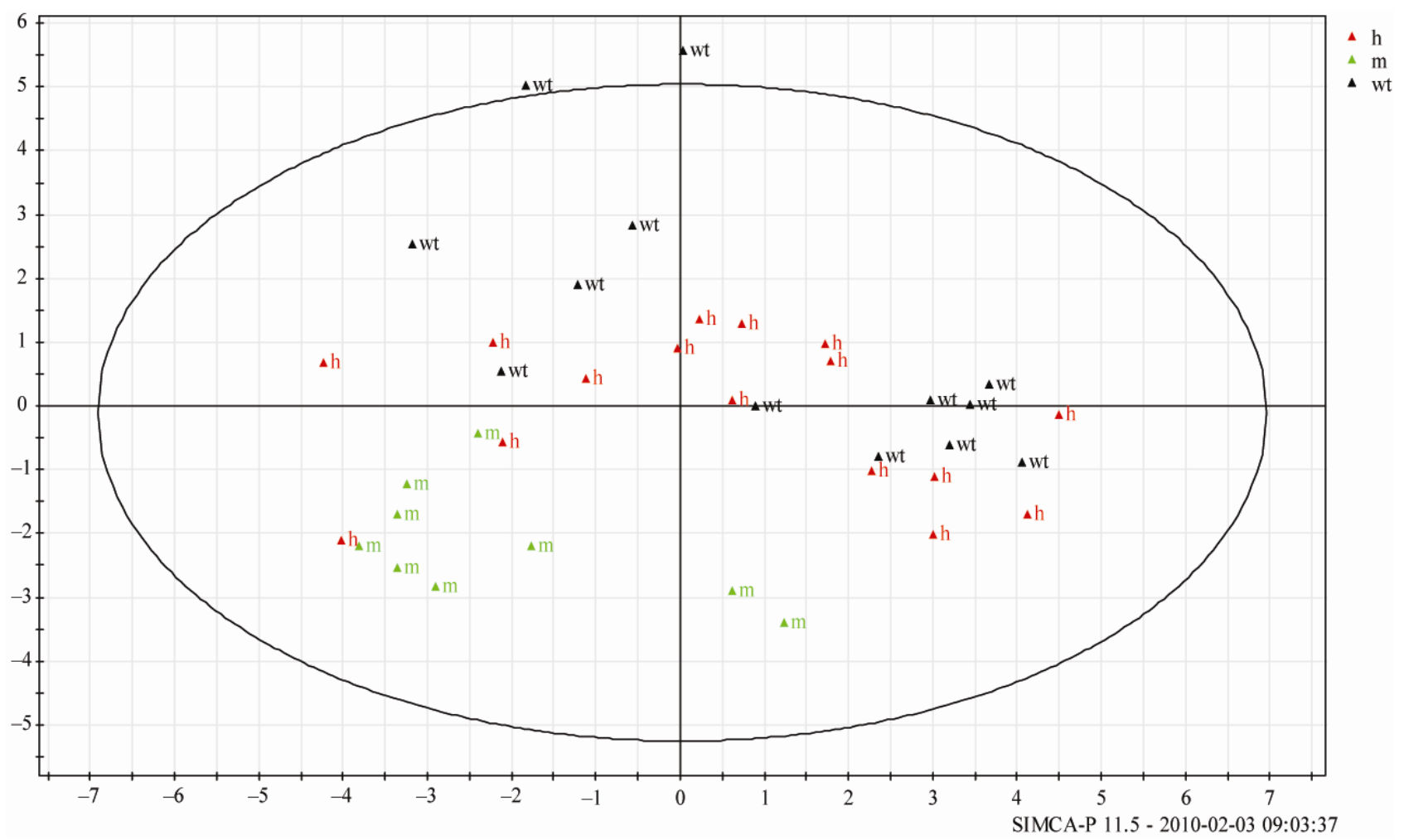

(c)

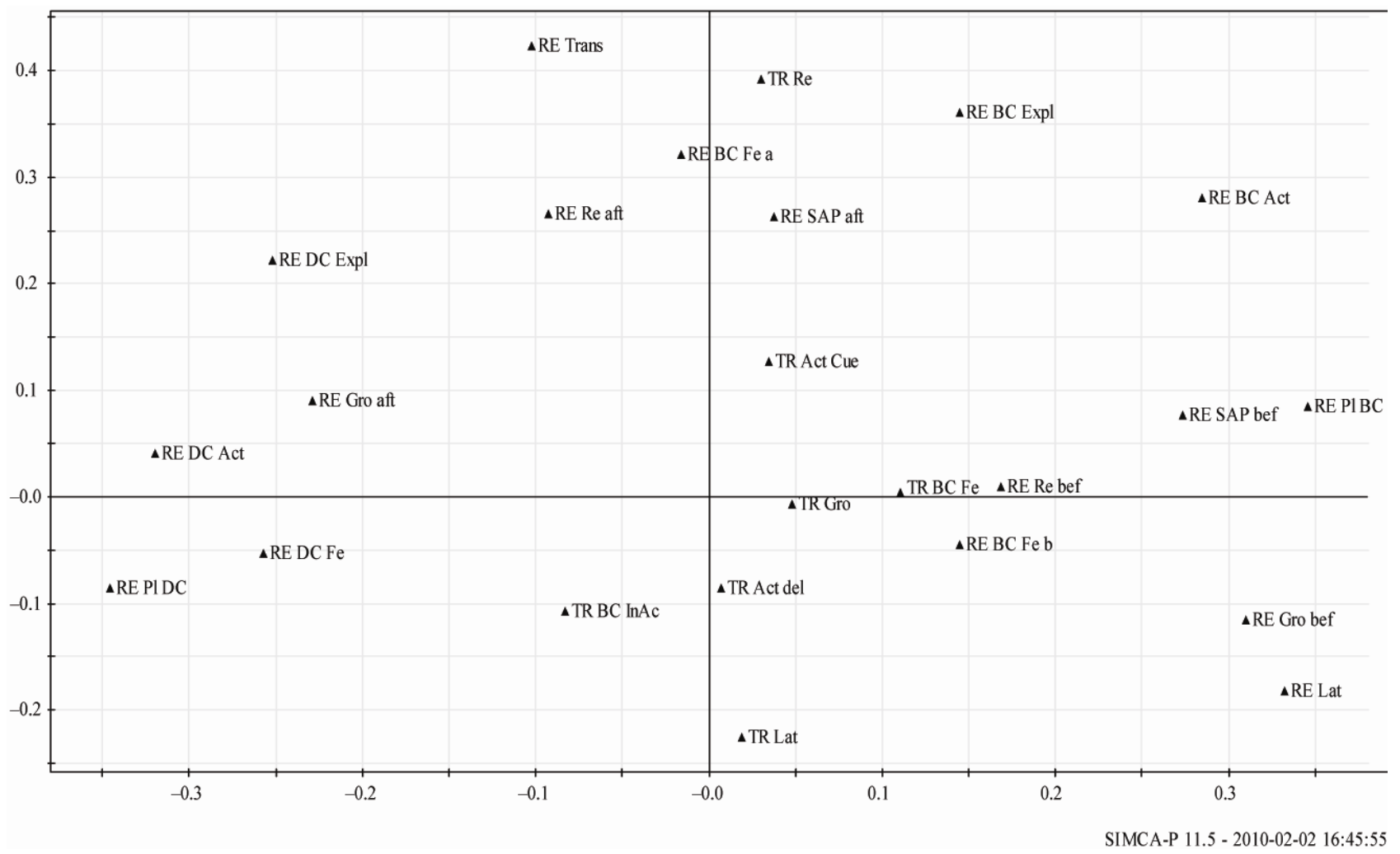

(d)

Figure 2. (a) Score plot PCA PA “low aversity” (Exp. 1); (b) Loading Plot PCA PA “low aversity” (Exp.1); (c) Score plot PCA PA “high aversity” (Exp. 2); (d) Loading Plot PCA PA “high aversity” (Exp. 2). 
In Exp 1. "low aversity cue", the genotypes did not form separate groups, although the location of the genotypes in the score plot were found in the same quadrants as in Exp 2. In the Exp. 2 "high aversity cue", three main groups were outlined, the $\mathrm{mceph} / \mathrm{mceph}$ mice in one group and two groups including both wild type and heterozygous mice. Both groups consisting of both wild type and heterozygous mice corresponded to a high frequency of risk assessments behaviors (RE SAP bef, RE SAP aft). The location of the mceph/mceph mice corresponded with a low or lack of risk assessment behaviors suggestive of a decreased defensive response to the aversive cue.

One of the groups with both wild type and heterozygous mice was located in correspondence with a high retention latency time (RE Lat), situated far out to the right in the loading plots in both trials. In both trials, risk assessment behaviors (RE SAP be), displacement behavior (RE Gro be) and anxiety-related behavior (RE BC $\mathrm{Fe}$ ) were clustered with or located nearby RE Lat. Individuals, more often heterozygous than wild type mice, with high retention latency also displayed behaviors related with a reactive stress coping strategy. The other group with both wild type and heterozygous mice was instead located in correspondence with a high frequency of exploratory behaviors (e g RE Tra) and risk assessment behaviors relating to a proactive stress coping strategy (Figure 2).

In Exp 1, the two principal components explained 30\% of the variance $\left(\mathrm{R}^{2} \mathrm{X}=0.303 ; \mathrm{Q}^{2} \mathrm{X}=-0.105\right.$ respectively) and in Exp. 2 it explained $47 \%$ of the variance $\left(\mathrm{R}^{2} \mathrm{X}=\right.$ $0.469 ; \mathrm{Q}^{2} \mathrm{X}=-0.172$ respectively) (Figure 2) and values of explained variation and predicted variation were within an appropriate range.

\subsection{Novel Cage Test}

In order to further analyse general exploratory behaviour in a non-aversive environment, the NCT was performed. Since the mceph/mceph mice showed changes of exploratory activity and risk-assessment behaviors in the PA task, more detailed behavioral data can be achieved in a neutral environment, compared to the short PA test performed in an aversive environment.

\subsubsection{Behavior during NCT}

Both during 3 and 6 weeks of age, the mice started the test sessions by walking followed by investigating and subsequently they paused to groom. Mice of 3 weeks of age spent most of the recording time on general activity combined with risk assessment behaviors whereas mice of 6 weeks of age were more engaged in explorative behaviors (Table 4; see Table 2 for ethogram).

Within group comparison over age showed that the mceph/mceph mice decreased their risk assessment and exploratory behaviors from 3 weeks to 6 weeks, whereas the wild type and heterozygous mice increased defensive behavior and general activity as well as decreased displacement behaviors (Table 4).

Compared to the heterozygous and wild type mice, the mceph/mceph mice had lower explorative behavior at 3 weeks of age. At 6 weeks of age they also had lower general activity and defensive behavior. Unlike the results obtained in PA, risk assessment behaviour did not differ in relation to genotype, probably related to the non-aversive nature of the NCT (Table 4).

\subsubsection{Comparison of the $m c e p h / m c e p h$, Heterozygous and Wild Type Mice in the NCT}

A PCA based on the NCT results presented in the Table 4 was used to identify relationships between the behavioral patterns and the genotype of the mice (see PCA for PA for further description of PCA). At 3 weeks of age there was no clear difference between the groups. However, at 6 weeks of age, there was a trend that the mceph/mceph mice formed a group that differed from the group including wild type and heterozygous mice. The individuals of the groups with both wild type and heterozygous mice were located corresponding to a high frequency of exploratory and risk assessments behaviors (e.g. 6DSAP 6FSAP, $6 \mathrm{~F}$ wallrearing and $6 \mathrm{~F}$ rearing). The location of the individuals of the mceph/mceph group corresponded to a long latency time of several behaviors (e.g. 6L wallrearing, 6L investigating) and long duration or frequency of seizures, freezing and motionless (e.g. 6D motionless, $6 \mathrm{~F}$ freeze an $6 \mathrm{D}$ seizure). Also at 3 weeks of age these behaviors were located corresponding to the mceph/mceph mice group (Figures 3(a)-(d)).

At 3 as well as of 6 weeks of age, the two principal components explained $58 \%$ of the variance $\left(\mathrm{R}^{2} \mathrm{X}=0.579\right.$; $\mathrm{Q}^{2} \mathrm{X}=0.067$ and $\mathrm{R}^{2} \mathrm{X}=0.581 ; \mathrm{Q}^{2} \mathrm{X}=0.365$ at 3 and 6 weeks of age, respectively) (Figures 3(a)-(d)) and values of explained variation and predicted variation were within an appropriate range.

\subsection{Behavioral Comparison of mceph/mceph, Heterozygous and Wild Type Mice}

The difference in the PA and NCT in overlapping behaviors is summarized in Table 5.

\subsection{Elevated Plus Maze (Exp. 2)}

Since most of the mceph/mceph mice developed seizures immediately when placed in the EPM, no relevant conclusion of anxiety-related behavior could be obtained. However, the heterozygous and the wild type mice did not differ in the EPM (data not shown). 
Table 4. Behaviors recorded during the NCT.

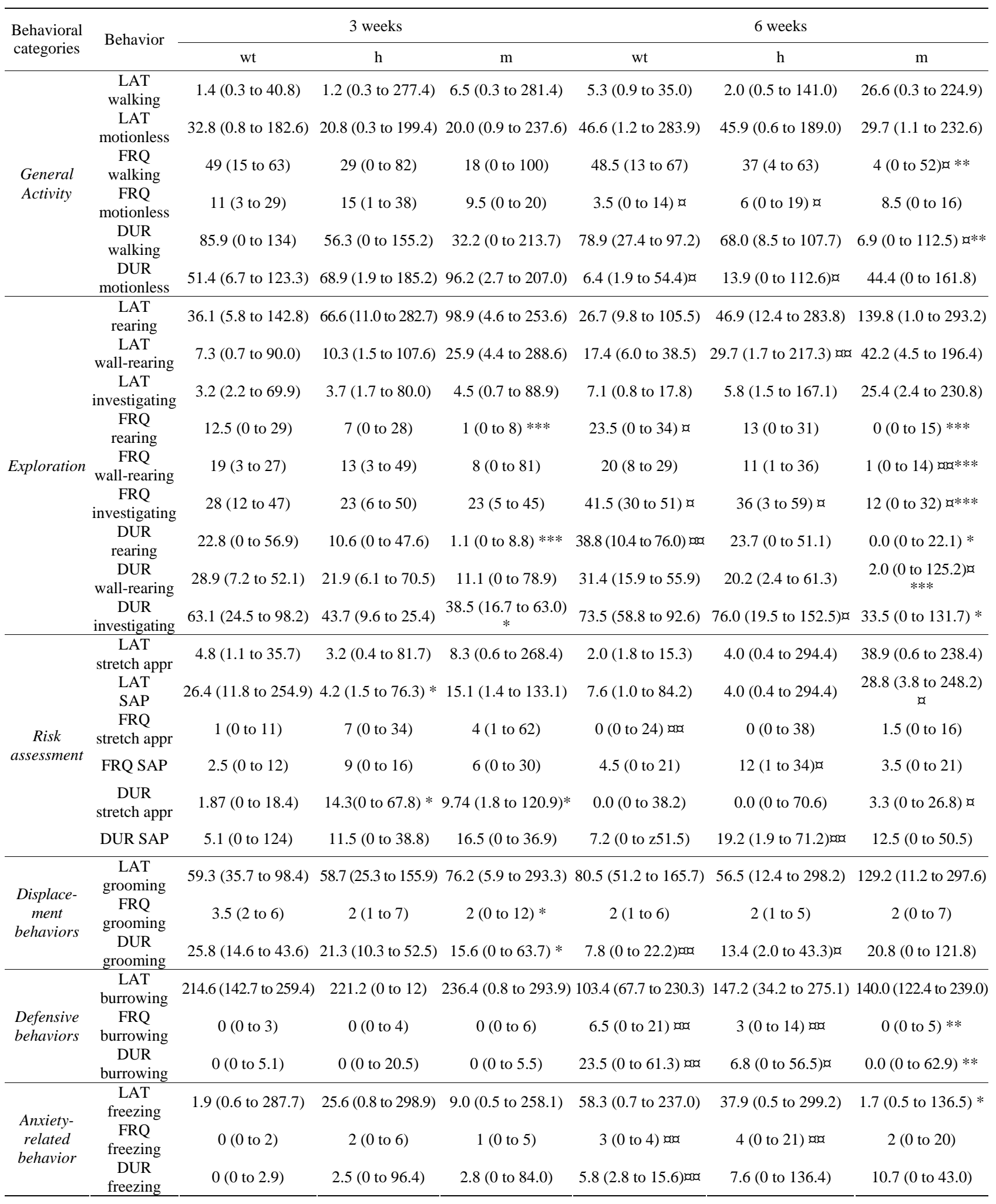

Table is showing results from the NCT. Data is presented as median (minimum to maximum), $a=p=0.05, a d a=p=0.01$, a a a $=p=0.001$ compared to 3 weeks of the same genotype. ${ }^{*}=\mathrm{p}=0.05, * *=\mathrm{p}=0.01, * * *=\mathrm{p}=0.001$ compared to wt. Abbreviations: LAT $=$ Latency time to first onset of the behavior (s), FRQ = Total frequency of the behavior (nr), DUR=Total Duration of the behavior (s), SAP-stretch approach posture. wt = wild type, $\mathrm{h}=\mathrm{heterozygote,} \mathrm{m}=m c e p h /$ mceph, $3 w=3$ weeks of age, $6 w=6$ weeks of age. Modified after $[28,40]$. 


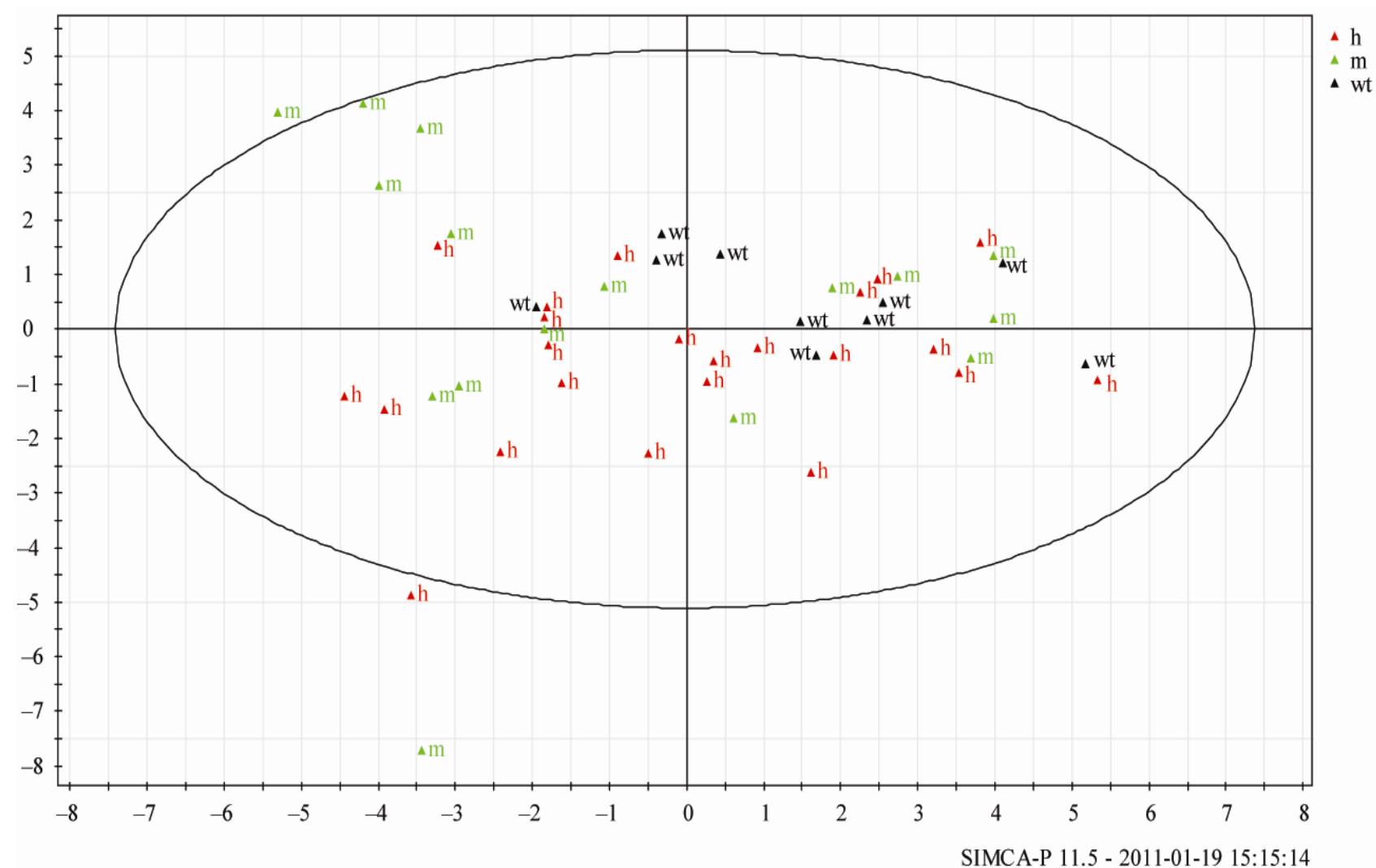

(a)

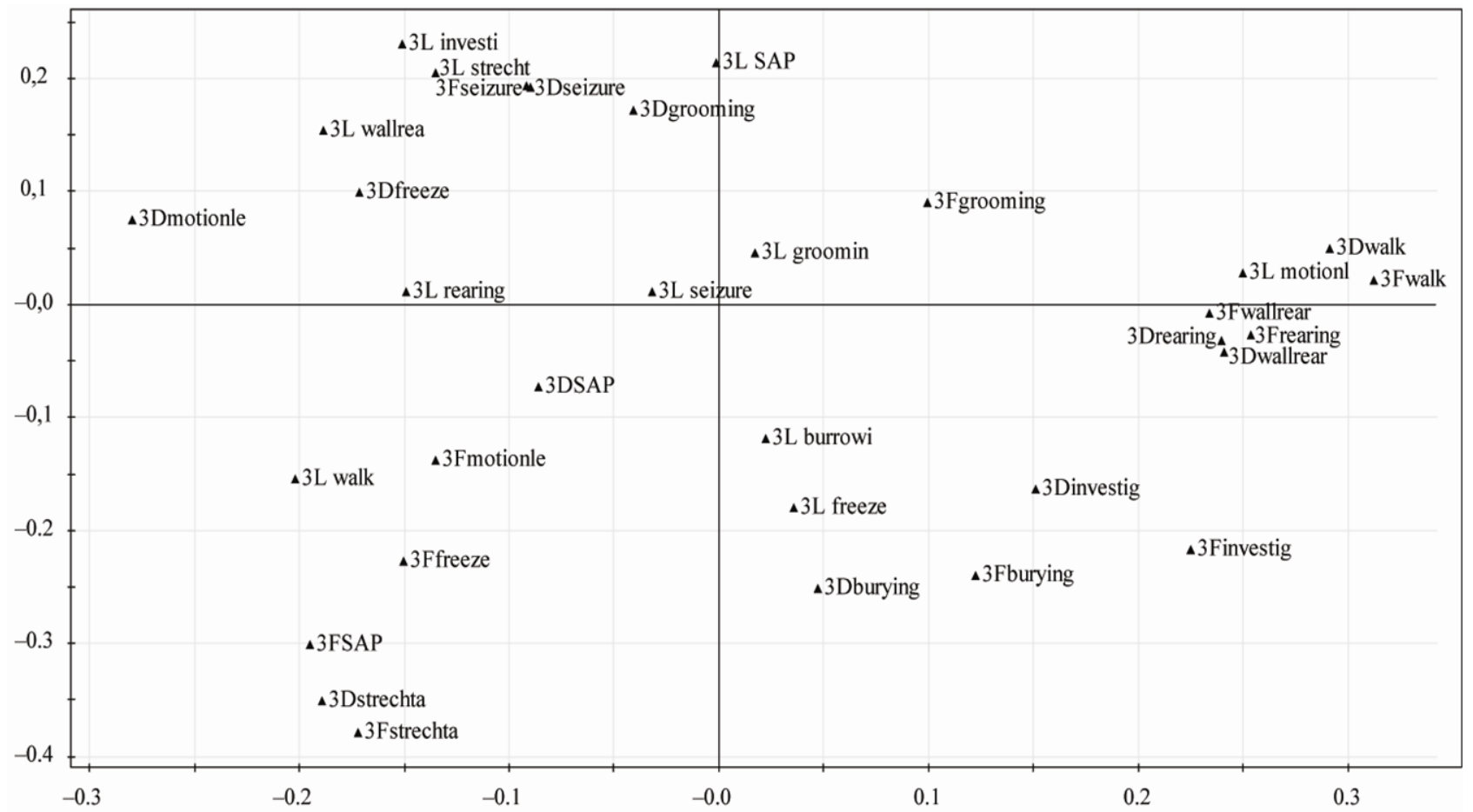

SIMCA-P 11.5 - 2011-01-19 15:14:40

(b) 


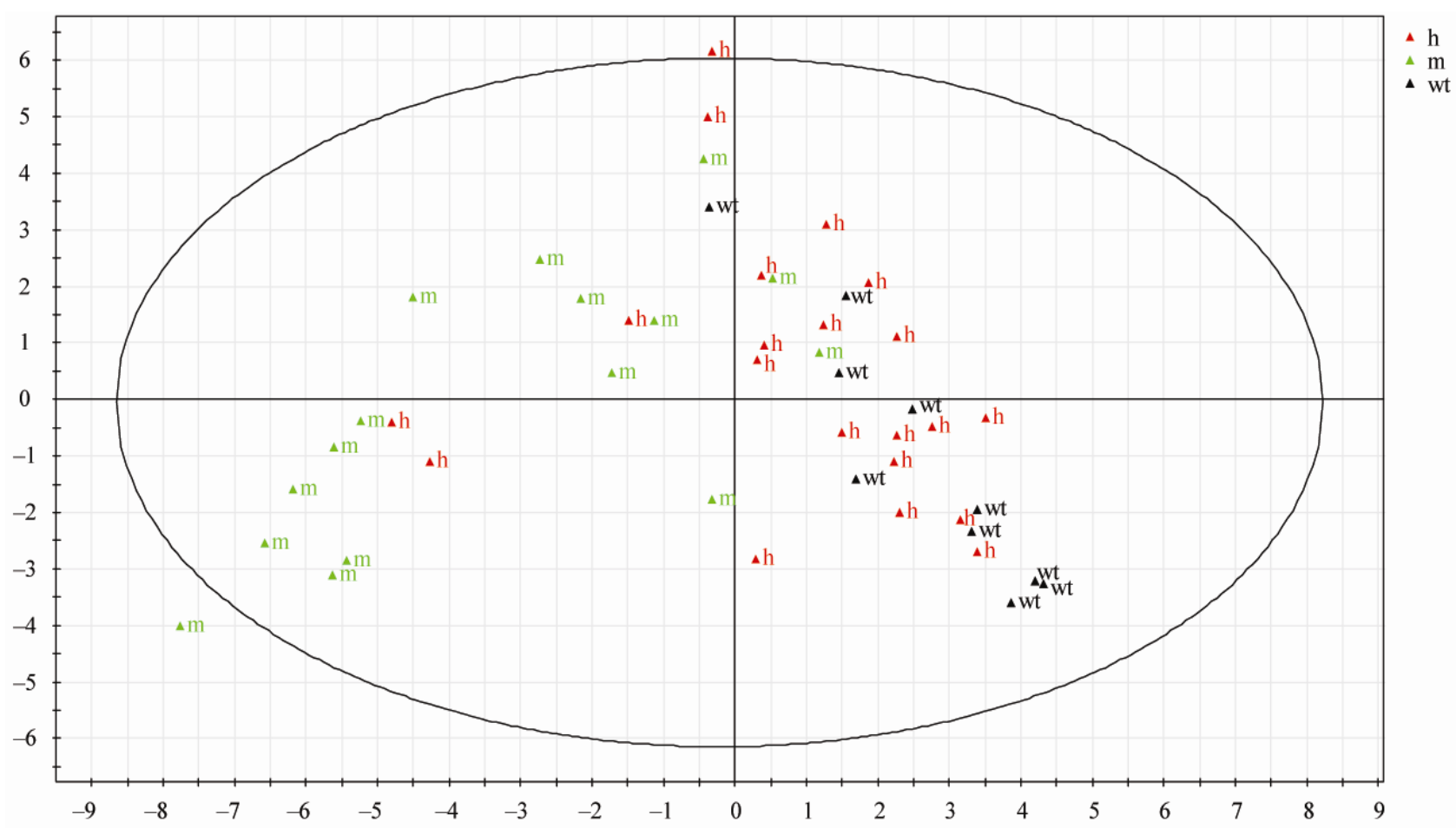

SIMCA-P 11.5 - 2011-01-19 15:22:29

(c)

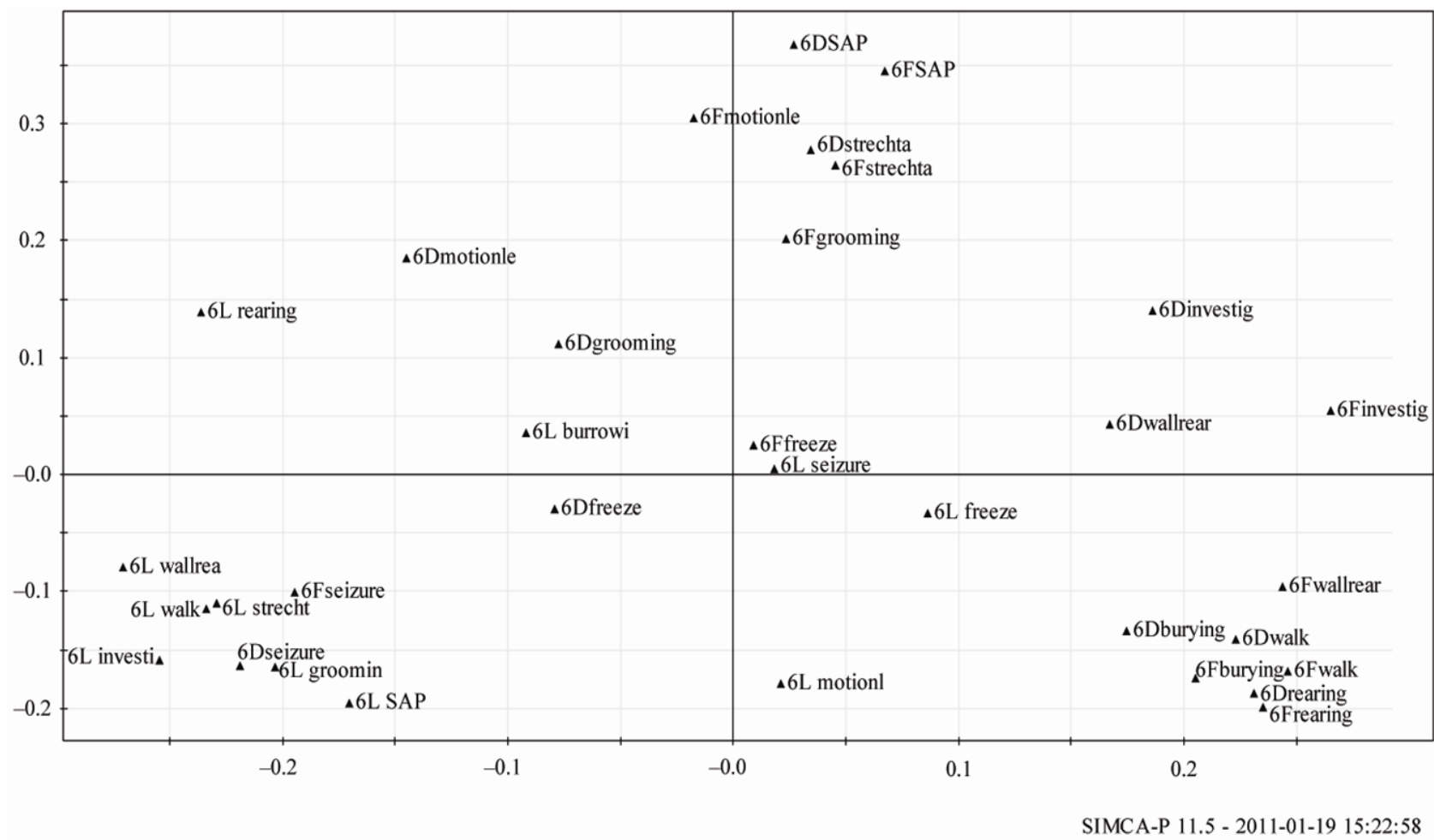

(d)

Figure 3. (a) Score plot PCA NCT 3 weeks of age; (b) Loading Plot PCA NCT 3 weeks of age; (c) Score plot PCA NCT 6 weeks of age; (d) Loading Plot PCA NCT 6 weeks of age. 
Table 5. Summary of behavioral differences between genotypes in the PA and NCT.

\begin{tabular}{cccc}
\hline Test & Behavioral categories & $\mathrm{m} \neq \mathrm{wt} \mathrm{h} ?$ & $\mathrm{wt} \neq \mathrm{h}$ ? \\
\hline PA & General Activity & $\mathrm{m}<\mathrm{h} \mathrm{wt}$ & - \\
NCT & Exploratoration & $\mathrm{m}<\mathrm{h} \mathrm{wt}$ & - \\
PA & & $\mathrm{m}<\mathrm{h} \mathrm{wt}$ & $\mathrm{wt}>\mathrm{h}$ \\
NCT & Risk assessment & $\mathrm{m}<\mathrm{h} \mathrm{wt}$ & - \\
PA & & $\mathrm{m}<\mathrm{h} \mathrm{wt}$ & - \\
NCT & Displacement behaviors & - & $\mathrm{wt}<\mathrm{h}$ \\
PA & & $\mathrm{m}<\mathrm{wt}$ & - \\
NCT & Defensive behaviors & $\mathrm{n} \mathrm{m}$ & $\mathrm{n} \mathrm{m}$ \\
PA & & $\mathrm{m}<\mathrm{h} \mathrm{wt}$ & - \\
NCT & Open-shelter & $\mathrm{n} \mathrm{m}$ & $\mathrm{n} \mathrm{m}$ \\
PA & & $\mathrm{m}<\mathrm{h}$ & - \\
$\mathrm{NCT}$ & Anxiety-related behavior & $\mathrm{m}<\mathrm{h}$ & - \\
PA & & - & - \\
NCT & & &
\end{tabular}

Table is showing differences recorded from the PA and NCT. Arrows indicate the direction of the difference. Abbreviations: NCT = Novel Cage, PA=Passive Avoidance, $\mathrm{n} \mathrm{m}=$ not measured, $\mathrm{wt}=$ wild type, $\mathrm{h}=$ heterozygotes, $\mathrm{m}=$ mceph $/$ mceph . Modified after $[28,40]$.

\subsection{Open Field (Exp. 2)}

The wild type mice visited the central region significantly $(p=0.022)$ more than the $m c e p h /$ mceph mice, and tendened to have more visits than the heterozygous mice ( $\mathrm{p}$ $=0.069$ ) (wild type: $59.9 \pm 16.1$; heterozygotes: $27.73 \pm$ 8.6; mceph/mceph: $17.40 \pm 10.1$; one way ANOVA $\mathrm{F}_{2,26}$ $=3.40 \mathrm{p}=0.049$ ). The distance travelled latency to the first visit and duration at each location did not differ significantly due to genotype (data not shown).

\subsection{Additional Phenotypical Characterisation (Exp. 1)}

\subsubsection{Seizures}

Unlike the wild type or heterozygous mice the mсерh/ mceph mice had seizures at 3 weeks or 6 weeks. At 3 weeks of age, the latency to first seizure was 32.6 (median, min: 5.4, max: 176.5) s and at 6 weeks it was 8.82 (median, min: 0.47, max: 101) s. At 3 weeks of age, the number of seizures was 0 (median, min: 0 , max: 7 ) and at 6 weeks 1 (median, min: 0, max: 101). At 3 weeks of age, duration of seizures was 0 (median, min: 0 , max: 76.6) $\mathrm{s}$ and at 6 weeks 81.8 (median, min: 0, max: 292.5) s. The seizures were mostly mild, in a typical seizure the hind legs of the mceph/mceph mouse cramped and were stretched out behind the body combined with the body shaking. Except for one mouse, all the mice remained conscious during the seizures. The first minutes after the seizure passed some mice walked or run very quickly. However, most of the mice sat still or groomed for some minutes after the seizure whereupon they continued with the previous behavioral repertoire.

\subsubsection{Phenotypical Characterisation}

There was no significant difference between heterozygous and wild type mice in body weight, number of individuals with teary eyes or number of vocalisations per individual, neither at 3 weeks nor at 6 weeks of age (Table 6).

However, compared to heterozygous and wild type mice the mceph/mceph mice had significantly lower body weight at 3 weeks (Table 6, one-way ANOVA $F_{2,46}=12.44$ $\mathrm{p}<0.001$ ) and 6 weeks (Table 6, one-way ANOVA $F_{2,46}$ $=14.60 \mathrm{p}<0.001$ ) of age, significantly higher number of individuals with teary eyes at 3 weeks (Table 6, H (2, N $=49)=18.30 \mathrm{p}<0.001)$ and at 6 weeks $($ Table $6, \mathrm{H}(2$, $\mathrm{N}=49)=39.60 \mathrm{p}<0.001$ ) and significantly lower number of vocalisations per individual at 3 weeks (Table 6, $\mathrm{H}$ $(2, \mathrm{~N}=49)=24.63 \mathrm{p}<0.001)$ but not at 6 weeks (Table 6, $\mathrm{H}(2, \mathrm{~N}=49)=2.15 \mathrm{p}=0.34)($ Table 6).

\subsubsection{Rotarod (Exp. 3)}

There was no significant difference in accelerating Rotarod performance between mceph/mceph and heterozygous mice neither in set 1 (mceph/mceph, $\mathrm{n}=4$; mean \pm SEM: $88.5 \pm 9.3$ and heterozygotes, $n=8 ; 104.8 \pm 10.2$ s; $\mathrm{p}=0.27)$ nor in set $2($ mceph $/$ mceph, $\mathrm{n}=6$; mean \pm SEM: $74.3 \pm 10.7$ and heterozygotes, $\mathrm{n}=10$; $99.1 \pm 8.9 \mathrm{~s} ; \mathrm{p}=$ 0.10 ) indicating that motor performance did not differ in mceph/mceph mice in contrast to the alterations of

Table 6. Phenotypical characterisation at 3 and 6 weeks.

\begin{tabular}{|c|c|c|c|c|c|c|}
\hline \multirow{2}{*}{$\begin{array}{l}\text { Phenotypical } \\
\text { characterisation }\end{array}$} & \multicolumn{3}{|c|}{3 weeks } & \multicolumn{3}{|c|}{6 weeks } \\
\hline & wt & $\mathrm{h}$ & $\mathrm{m}$ & wt & $\mathrm{h}$ & $\mathrm{m}$ \\
\hline Body Weight (g) & $10.6 \pm 0.47$ & $9.9 \pm 0.26$ & $8.2 \pm 0.34 * * *$ & $20.3 \pm 0.68$ & $18.7 \pm 0.50$ & $15.7 \pm 0.55^{* * *}$ \\
\hline $\begin{array}{l}\text { Teary eyes } \\
\text { (nr/total nr) }\end{array}$ & $1 / 10$ & $1 / 23$ & $10 / 16^{* *}$ & $0 / 10$ & $0 / 23$ & $14 / 16^{* * *}$ \\
\hline
\end{tabular}

Table is showing phenotypical characterisation measured after Novel Cage test. Data is presented as means \pm SEM or nr of individuals/total nr of individuals. $\mathrm{wt}=$ wild type, $\mathrm{h}=$ heterozygotes, $\mathrm{m}=$ mceph $/$ mceph, ${ }^{* *}=\mathrm{p}=0.01$, *** $=\mathrm{p}=0.001$ compared to $\mathrm{mceph} / \mathrm{mceph}$. 
spontaneous motor activity these mice display in other test (see above).

\subsection{Stereology (Exp. 4)}

There was no significant difference in the number of NeuNpositive neurons in the hippocampus of the wild type and heterozygous mice (wild type: $102736.35 \pm 15089.9$; heterozygotes: $108493.55 \pm 22479.3$; one-way ANOVA $F_{1,14}=0.045 p=0.83$ ). The number of NeuN-positive neurons in the hippocampus of the mceph/mceph has been reported previously and was found to be increased (see introduction).

\section{Discussion}

The aim of the present study was to analyse the effects of genetically induced potassium-ionchannelopathy on behavior and hippocampal cognitive function. The BALB/cByJ-Kv1.1 ${ }^{\text {mceph/mceph }}$ with a germline complete lack of functional Kv1.1, displaying chronic TLE without apparent neurodegeneration, showed impaired memory in the PA task. The mceph/mceph mice did not show a learning-induced increase in step-through latency into the dark compartment at the retention test compared to training. In contrast, in wild type and heterozygous, $K v 1.1^{\text {mceph/+ }}$ mice, the step-through latency time was significantly increased at retention compared to training, indicative of successful learning to avoid the aversive context. To further strengthen the analysis, the behavioral data recorded during the PA was subjected to multivariate analysis. This analysis indicated that the mceph/mceph mice displayed a lower frequency of risk assessment behaviors compared to wild type and heterozygous mice.

In the NCT the mceph/mceph mice were characterised by a low general activity and exploratory behavior at 3 weeks of age and from 6 weeks of age also low defensive behavior. Although the mceph/mceph mice had mild seizures, their motor coordination was not affected. The heterozygous mice showed indications of lower explorative behaviors and higher risk assessment behaviors compared to wild type mice in the PA. The mceph/mceph mice have been shown to have an excessive number of NeuN-immunoreactive neurons in the hippocampus. However, the number of NeuN-immunoreactive cells in the DG of the heterozygous mice did not differ from the wild type mice, considered with or unchanged hippocampal volume [14].

Compared to wild type and heterozygous mice the mceph/mceph mice had a low frequency of the risk assessment behavior SAPs in the PA test, unlike results obtained in the non-aversive NCT test. SAP is interpreted as the intention of the mouse to assess the environment in a safe manner, motivated by a state of fear. The mceph/mceph mice did not display displacement behaviors (grooming) before step-through and they did not transfer back to the bright compartment of the PA apparatus. Instead the mceph/mceph mice spent more time in the dark compartment, which they explored, probably due to a lack of fear. This suggests that the mceph/mceph mice prefer the dark compartment despite the aversive cue received there $24 \mathrm{~h}$ earlier. Moreover, the activity of the mceph/mceph mice in response to the aversive cue as well as during the 60s delay in the dark compartment after the aversive cue, was either increased or not differed from the activity of wild type and heterozygous mice, indicating unaltered response to the aversive stimulus. Therefore, the failure to learn the PA memory task appears not to be a result of altered pain perception, but related to impaired memory retention of the aversive context.

Human TLE patients suffer from impaired memory function [41-42] as well as rodents with spontaneous or provoked epilepsy [17-19]. The behavioral phenotype of the mсерh/mceph mice may reflect a dysfunction in hippocampal excitability. Recent electrophysiological studies in the mceph/mceph hippocampus (Fisahn et al., submitted), indicate disturbances in gamma oscillations, i.e. synchronous activity in the gamma frequency-range that depends directly on network excitability. Gamma oscillations play an important role in higher processes in the brain such as learning, memory, cognition and perception $[44,45]$. This abnormal network excitability may in part result from the excessive adult-borne hippocampal neurons in mceph/mceph. Seizure-induced new neurons are reported to be less excitable and aberrant in their polarity, migration and integration pattern compared to non-seizure-induced adult-born neurons, although stably integrated into the hippocampal circuitry within $24 \mathrm{~h}$ to weeks [46-48], in contrast to neurogenesis induced by running and/or enriched environment [49].

Both the wild type and the heterozygous mice increased their step-through latencies at retention compared to training. However, both groups displayed a large variation of the step-though latency. The ethological study revealed that both groups displayed risk assessment behaviors reflecting the remembrance of the earlier presented aversive cue. The large variation of the step-through latency is most likely a result of different stress coping strategies to the aversive cue. Individuals with short step-through latency often had a high frequency of exploratory behaviors, including transfers inbetween the compartments, suggesting a proactive coping style. In contrast, individuals with long step-through latency often had a higher frequency of anxiety-related behaviors, suggesting a reactive coping style. Stress coping strategies are related to the fight-andflight responses. A reactive coping strategy is associated 
with an increased immobility and freezing in order to attempt playing dead or outwait stressful stimulus. A proactive coping strategy is associated either with an assessment of the risk to investigate the environment by exposing defensive behaviors such as exploring, rearing and SAP, or with aggressive and aversive behaviors [50]. This indicates that also mice with shorter step-through latencies at retention may have acquired the PA task with successful memory consolidation, implying the importance of combining the step-through latency measure with ethologically based measures when examining emotional memory functions.

In the NCT exploratory and defensive behavior as well as general activity was low in the mceph/mceph mice. Explorative behaviour refers to activities aiming at increasing the knowledge of the surrounding environment for safety assessment, e.g. rearing, sniffing and ambulation. Also mice with seizures provoked by a hippocampal pilocarpine injection reduced their explorative behavior such as rearing in the OF and frequency of transfer measured in light-dark box [18,19,51]. The mceph/mceph mice had long periods of grooming, rather than short bouts. This may be interpreted as cleaning of the body, in contrast to short bouts that is associated with displacement behavior [52], which may indicate fear and is displayed when the animal is in conflict of what behavior to display. The lack of displacement behavior in the mceph/mceph mice may indicate low stress levels related to the context of the behavioral tests. Although the mceph/mceph displayed lower levels of stress related behaviors, they had an increased frequency of freezing, which probably is related to lowering of subthresholds for seizures provoked by light exposure. Also mice with seizures provoked by a hippocampal pilocarpine injection have increased scores of freezing [51]. The general activity of the mceph/mceph mice was low compared to wild type and heterozygous mice also when behavioral scoring was adjusted for reoccurring seizures. In contrast, in the OF illuminated with a red light bulb, general activity of the mceph/mceph mice did not differ from heterozygous and wild type mice. Exposure to the light may have provoked seizures in the mceph/mceph mice that disturbed the perception or processing of the contextual stimuli and their coping to the aversive cue in the PA task. This probably also explains the behavioral phenotype of the mceph/mceph mice including impaired memory, which seems to reflect several of the behavioral and cognitive disturbances associated with epilepsy in humans.

\section{Conclusions}

In this study, the mceph/mceph mouse model for epilepsy with potassium channelopathy was assessed for hippo- campal-dependent emotional memory function in the PA task combined with a detailed behavioral analysis, performed both in the aversive context (PA) and in a neutral environment (NCT). In contrast to wild-type and heterozygous mice, the mceph/mceph mice failed to acquire avoidance of the environment associated with contextual fear in the PA retention test. Thus, the mceph/mceph mice displayed unchanged step-through latency at retention compared to training as well as low exploration and riskassessment behaviors. The multivariate analysis indicates that alterations of exploration and risk-assessment behaviors are key variables for analysing deficits in memory processing. Also, in the NCT the mceph/mceph mice were characterised by a pattern of explorative, locomotor and risk assessment behaviors indicative of a blunted response to aversive stimuli.

In conclusion, the results suggest that the mceph/mceph mice have a deficit in behavioural defensive responses to aversive stimuli probably as a result of impairments in emotional processing and memory. This suggests that the mсерh/mceph mice may be a relevant animal model for studying of limbic system mechanisms involved in emotional and cognitive problems related to epilepsy.

\section{Acknowledgements}

We thank Professor Kristina Dahlborn for access to the Simpca + software (Umetrics ${ }^{\circledR}$ ), and Dr Elin ElvanderTottie and Dr Eugenia Kuteeva for valuable comments on the manuscript. This study was supported by The Swedish Research Council, Karolinska Institutet Foundations and Thuring Foundations.

\section{References}

[1] J. F. van Brederode, J. M. Rho, R. Cerne, B. L. Tempel and W. J. Spain, "Evidence of Altered Inhibition in Layer V Pyramidal Neurons from Neocortex of Kcna1-Null Mice,” Neuroscience, Vol. 103, No. 4, 2001, pp. 921-929. doi:10.1016/S0306-4522(01)00041-0

[2] V. Lopantsev, B. L. Tempel and P. A. Schwartzkroin, "Hyperexcitability of CA3 Pyramidal Cells in Mice LackIng the Potassium Channel Subunit Kv1.1,” Epilepsia, Vol. 44, No. 12, 2003, pp. 1506-1512. doi:10.1111/j.0013-9580.2003.44602.x

[3] H. M. Brew, J. L. Hallows and B. L.Tempel, "Hyperexcitability and Reduced Low Threshold Potassium Currents in Auditory Neurons of Mice Lacking the Channel Subunit Kv1.1,” Journal of Physiology, Vol. 548, 2003, pp. 1-20. doi:10.1113/jphysiol.2002.035568

[4] S. M. Zuberi, L. H. Eunson, A. Spauschus, R. De Silva, J. Tolmie, N. W. Wood, R. C. McWilliam, J. B. Stephenson, D. M. Kullmann and M. G. Hanna, "A Novel Mutation in the Human Voltage-Gated Potassium Channel Gene (Kv1.1) Associates with Episodic Ataxia Type 1 and Sometimes 
with Partial Epilepsy,” Brain, Vol. 122, No. 5, 1999, pp. 817- 825. doi:10.1093/brain/122.5.817

[5] L. H. Eunson, R. Rea, S. M. Zuberi, S. Youroukos, C. P. Panayiotopoulos and R. Liguori, "Clinical, Genetic, and Expression Studies of Mutations in the Potassium Channel Gene KCNA1 Reveal New Phenotypic Variability,” Annals of Neurology, Vol. 48, No. 4, 2000, pp. 647-656. doi:10.1002/1531-8249(200010)48:4<647::AID-ANA12 >3.0.CO;2-Q

[6] A. S. Persson, G. Klement, M. Almgren, K. Sahlholm, J. Nilsson, S. Petersson, P. Århem, M. Schalling and C. Lavebratt, "A Truncated Kv1.1 Protein in the Brain of the Megencephaly Mouse: Expression and Interaction,” BMC Neuroscience, Vol. 6, 2005, p. 65. doi:10.1186/1471-2202-6-65

[7] S. Petersson, A.S. Persson, J. Johansen, M. Ingvar, M. Schalling and C. Lavebratt, "Truncation of the ShakerLike Voltage-Gated Potassium Channel, Kv1.1, Causes Megencephaly,” European Journal of Neuroscience, Vol. 18, No. 12, 2003, pp. 3231-3240. doi:10.1111/j.1460-9568.2003.03044.x

[8] S. L. Smart, V. Lopantsev, C. L. Zhang, C. A. Robbins, H. Wang, S. Y. Chiu, P. A. Schwartzkroin, A. Messing and B. L. Tempel, "Deletion of the Kv1.1 Potassium Channel Causes Epilepsy in Mice,” Neuron, Vol. 20, No. 4, 1998, pp. 809-819. doi:10.1016/S0896-6273(00)81018-1

[9] A. Gambardella, A. Labate, A. Giallonardo and U. Aguglia, "Familial Mesial Temporal Lobe Epilepsies: Clinical and Genetic Features,” Epilepsia, Vol. 50, Suppl. 5, 2009, pp. 55-57. doi:10.1111/j.1528-1167.2009.02123.x

[10] S. Jessberger, B. Römer, H. Babu and G. Kempermann, "Seizures Induce Proliferation and Dispersion of Doublecortin-Positive Hippocampal Progenitor Cells,” Experimental Neurology, Vol. 196, No. 2, 2005, pp. 342351. doi:10.1016/j.expneurol.2005.08.010

[11] S. Petersson, C. Lavebratt, M. Schalling and T. Hökfelt, "Expression of Cholecystokinin, Enkephalin, Galanin and Neuropeptide Y Is Markedly Changed in the Brain of the Megencephaly Mouse,” Neuroscience, Vol. 100, No. 29, 2000, pp. 297-317. doi:10.1016/S0306-4522(00)00285-2

[12] M. Diez, P. Schweinhardt, S. Petersson, F.-H. Wang, C. Lavebratt, M. Schalling, M., T. Hökfelt and C. Spenger, "MRI and in Situ Hybridization Reveal Early Disturbances in Cerebral Size and Gene Expression in the Megencephalic (mceph/mceph) Mouse," European Journal of Neuroscience, Vol. 18, No. 12, 2003, pp. 3218-3230. doi:10.1111/j.1460-9568.2003.02994.x

[13] A. S. Persson, E. Westman, F.-H. Wang, F. H. Khan, C. Spenger and C. Lavebratt, "Kv1.1 Null Mice Have Enlarged Hippocampus and Ventral Cortex," BMC Neuroscience, Vol. 8, 2007, p. 10. doi:10.1186/1471-2202-8-10

[14] M. Almgren, A. S. Persson, C. Fenghua, B. M. Witgen, M. Schalling, J. R. Nyengaard and C. Lavebratt, "Lack of Potassium Channel Induces Proliferation and Survival Causing Increased Neurogenesis and Two-Fold Hippocampus Enlargement,” Hippocampus, Vol. 17, No. 4, 2007, pp. 292-304. doi:10.1002/hipo.20268
[15] M. Almgren, M. Schalling and C. Lavebratt, “Idiopathic Megalencephaly-Possible Cause and Treatment Opportunities: From Patient to Lab,” European Journal of Paediatric Neurology, Vol. 1, No. 26, 2008, pp. 438-445. doi:10.1016/j.ejpn.2007.11.008

[16] E. D. Burg, C. V. Remillard and J. X. Yuan, "K + Channels in Apoptosis," The Journal of Membrane Biology, Vol. 209, No. 1, 2006, pp. 3-20. doi:10.1007/s00232-005-0838-4

[17] M. Lynch, U. Sayin, J. Bownds, S. Janumpalli and T. Sutula, "Long-Term Consequences of Early Postnatal Seizures on Hippocampal Learning and Plasticity,” European Journal of Neuroscience, Vol. 12, No. 7, 2000, pp. 2252-2264. doi:10.1046/j.1460-9568.2000.00117.x

[18] C. J. Müller, I. Gröticke, M. Bankstahl and W. Löscher, "Behavioral and Cognitive Alterations, Spontaneous Seizures, and Neuropathology Developing after a PilocarpineInduced Status Epilepticus in C57BL/6 Mice,” Experimental Neurology, Vol. 219, No. 1, 2009, pp. 284-297. doi:10.1016/j.expneurol.2009.05.035

[19] I. Gröticke, K. Hoffmann and W. Löscher, "Behavioral Alterations in a Mouse Model of Temporal Lobe Epilepsy in Mice Induced by Intrahippocampal Injection of Kainite,” Experimental Neurology, Vol. 213, No. 1, 2008, pp. 71-83. doi:10.1016/j.expneurol.2008.04.036

[20] M. Cãrreno, A. Donaire and R. Sánchez-Carpintero, "Cognitive Disorders Associated with Epilepsy: Diagnosis and Treatment,” Neurologist, Vol. 14, No. 6, 2008, pp. S26-S34. doi:10.1097/01.nrl.0000340789.15295.8f

[21] J. E. LeDoux, "Emotional Memory Systems in the Brain," Behavioural Brain Research, Vol. 58, No. 1-2, 1993, pp. 69-79. doi:10.1016/0166-4328(93)90091-4

[22] R. G. Morris, "Developments of a Water-Maze Procedure for Studying Spatial Learning in the Rat,” Journal of Neu roscience Methods, Vol. 11, No. 1, 1984, pp. 47-60. doi:10.1016/0165-0270(84)90007-4

[23] B. Milner, L. R. Squire and E. R. Kandel, "Cognitive Neuroscience and the Study of Memory," Neuron, Vol. 20, No. 3, 1998, pp. 445-468. doi:10.1016/S0896-6273(00)80987-3

[24] S. O. Ögren, T. M. Eriksson, E. Elvander-Tottie, C. D’Ad- dario, J. C. Ekström, P. Svenningsson, B. Meister, J. Kehr and O. Stiedl, "The Role of 5-HT(1A) Receptors in Learning and Memory,” Behavioural Brain Research, Vol. 195, No. 1, 2008, pp. 54-77. doi:10.1016/j.bbr.2008.02.023

[25] B. P. Hermann, J. J. Lin, J. E. Jones and M. Seidenberg, "The Emerging Architecture of Neuropsychological Impairment in Epilepsy,” Neurologic Clinics, Vol. 27, No. 4, 2009, pp. 881-907. doi:10.1016/j.ncl.2009.08.001

[26] C. Sgobio, V. Ghiglieri, C. Costa, V. Bagetta, S. Siliquini, I. Barone, M. Di Filippo, F. Gardoni, E. D. Gundelfinger, M. Di Luca, B. Picconi and P. Calabresi, "Hippocampal Synaptic Plasticity, Memory, and Epilepsy: Effects of Long-Term Valproic Acid Treatment,” Biological Psychiatry, Vol. 67, No. 6, 2010, pp. 567-574. 
doi:10.1016/i.biopsych.2009.11.008

[27] L. R. Donahue, S. A. Cook, K. R. Johnson, R. T. Bronson and M. T. Davisson, "Megencephaly: A New Mouse Mutation on Chromosome 6 That Causes Hypertrophy of the Brain,” Mammalian Genome, Vol. 7, No. 12, 1996, pp. 871-876. doi:10.1007/s003359900259

[28] H. Augustsson, K. Dahlborn and B. J. Meyerson, "Exploration and Risk Assessment in Female Wild House Mice (Mus Musculus Musculus) and Two Laboratory Strains,” Physiology \& Behavior, Vol. 84, No. 2, 2005, pp. 265-277. doi:10.1016/j.physbeh.2004.12.002

[29] P. J. Baarendse, G. van Grootheest, R. F. Jansen, A. W. Pieneman, S. O. Ögren, M. Verhage and O. Stiedl, "Differential Involvement of the Dorsal Hippocampus in Passive Avoidance in C57bl/6J and DBA/2J Mice," Hippocampus, Vol. 18, No. 1, 2008,pp. 11-19. doi:10.1002/hipo.20356

[30] B. L. Finlay and R. B. Darlington, "Linked Regularities in the Development and Evolution of Mammalian Brains," Science, Vol. 268, No. 5217, 1995, pp. 1578-1584. doi:10.1126/science.7777856

[31] N. Madjid, E. E. Tottie, M. Lüttgen, B. Meister, J. Sandin, A. Kuzmin, O. Stiedl, S. O. Ögren, "5-Hydroxytryptamine 1A Receptor Blockade Facilitates Aversive Learning in Mice: Interactions with Cholinergic and Glutamatergic Mechanisms," The Journal of Pharmacology and Experimental Therapeutics, Vol. 316, No. 2, 2006, pp. 581-591. doi:10.1124/jpet.105.092262

[32] T. M. Eriksson, N. Madjid, E. Elvander-Tottie, O. Stiedl, P. Svenningsson and S. O. Ögren, "Blockade of 5-HT 1B Receptors Facilitates Contextual Aversive Learning in Mice by Disinhibition of Cholinergic and Glutamatergic Neurotrans-Mission,” Neuropharmacology, Vol. 54, No. 7, 2008, pp. 1041-1050. doi:10.1016/j.neuropharm.2008.02.007

[33] O. Stiedl, I. Misane, P. Tovote, A. Ronnenberg, J. Spiess and S. O. Ögren, "Involvement of NMDA Receptors in the Dorsal Hippocampus in Passive Avoidance Learning in Mice," Society for Neuroscience Abstract, Vol. 773, 2004, p. 12.

[34] J. M. Marques, I. A. Olsson, S. O. Ögren and K. Dahlborn, "Evaluation of Exploration and Risk Assessment in PreWeaning Mice Using the Novel Cage Test," Physiology \& Behavior, Vol. 93, No. 1-2, 2008, pp. 139-147. doi:10.1016/j.physbeh.2007.08.006

[35] E. B. Ottoni, "EthoLog 2.2: A Tool for the Transcription and Timing of Behavior Observation Sessions," Behavior Research Methods, Instruments, \& Computers, Vol. 32, No. 3, 2000, pp. 446-449. doi:10.3758/BF03200814

[36] K. Franklin and G. Paxinos, "The Mouse Brain in StereoTaxic Coordinates,” Academic Press, San Diego, 1997.

[37] E. Åberg, C. P. Hofstetter, L. Olson and S. Brené, “Moderate Ethanol Consumption Increases Hippocampal Cell Proliferation and Neurogenesis in the Adult Mouse," International Journal of Neuropsychopharmacology, Vol. 8 No. 4, 2005, pp. 557-567. doi:10.1017/S1461145705005286
[38] M. J. West and H. J. Gundersen, "Unbiased Stereological Estimation of the Number of Neurons in the Human Hippocampus," Journal of Comparative Neurology, Vol. 296, No. 1, 1990, pp. 1-22. doi:10.1002/cne.902960102

[39] J. E. Jackson, “A User's Guide to Principal Components,” John Wiley \& Sons Inc, New York, 1991. doi:10.1002/0471725331

[40] E. Roman and G. Colombo, "Lower Risk Taking and ExPloratory Behavior in Alcohol-Preferring sP Rats than in Alcohol Non-Preferring sNP Rats in the Multivariate Concentric Square Field (MCSF) Test,” Behavioural Brain Research, Vol. 205, No. 1, 2009, pp. 249-58. doi:10.1016/j.bbr.2009.08.020

[41] A. R. Giovagnoli and G. Avanzini, "Quality of Life and Memory Performance in Patients with Temporal Lobe EpilLepsy,” Acta Neurologica Scandinavica, Vol. 101, No. 5, 2000, pp. 295-300. doi:10.1034/j.1600-0404.2000.90257a.x

[42] U. Hlobil, C. Rathore, A. Alexander, S. Sarma and K. Radhakrishnan, "Impaired Facial Emotion Recognition in Patients with Mesial Temporal Lobe Epilepsy Associated with Hippocampal Sclerosis (MTLE-HS): Side and Age at Onset Matters,” Epilepsy Research, Vol. 80, No. 2-3, 2008, pp. 150-157.

[43] V. Tuchscherer, M. Seidenberg, D. Pulsipher, M. Lancaster, L. Guidotti and B. Hermann, "Extrahippocampal Integrity in Temporal Lobe Epilepsy and Cognition: Thalamus and Executive Functioning," Epilepsy \& Behaviour, Vol. 17, No. 4, 2010, pp. 478-482. doi:10.1016/j.yebeh.2010.01.019

[44] C. M. Gray and W. Singer, "Stimulus-Specific Neuronal Oscillations in Orientation Columns of Cat Visual Cortex," Proceedings of the National Academy of Sciences of the United States of America, Vol. 86, No. 5, 1989, pp. 1698-1702.

[45] A. K. Engel and W. Singer, "Temporal Binding and the Neural Correlates of Sensory Awareness," Trends in Cognitive Sciences, No. 5, No. 1, 2001, pp. 16-25.

[46] K. Jakubs, A. Nanobashvili, S. Bonde, C. T. Ekdahl, Z. Kokaia, M. Kokaia and O. Lindvall, "Environment MatTers: Synaptic Properties of Neurons Born in the Epileptic Adult Brain Develop to Reduce Excitability,” Neuron, Vol. 52, No. 6, 2006, pp. 1047-1059.

doi:10.1016/j.neuron.2006.11.004

[47] L. S. Overstreet-Wadiche, D. A. Bromberg, A. L. Bensen and G. L. Westbrook, "Seizures Accelerate Functional InTegration of Adult-Generated Granule Cells,” The Journal of Neuroscience, Vol. 26, No. 15, 2006, pp. 40954103. doi:10.1523/JNEUROSCI.5508-05.2006

[48] S. Jessberger, C. Zhao, N. Toni, G. D. Clemenson, Y. Li, and F. H. Gage, "Seizure-Associated, Aberrant Neurogenesis in Adult Rats Characterized with Retrovirus-Mediated Cell Labelling,” The Journal of Neuroscience, Vol. 29, No. 35, 2007, pp. 9400-9407.

[49] B. Steiner, S. Zurborg, H. Hörster, K. Fabel and G. Kempermann, "Differential 24 h Responsiveness of Prox1-Expressing Precursor Cells in Adult Hippocampal Neurogenesis to Physical Activity, Environmental Enrichment, 
and Kainic Acid-Induced Seizures," Neuroscience, Vol. 154, No. 2, 2008, pp. 521-529.

doi:10.1016/j.neuroscience.2008.04.023

[50] J. M. Koolhaas, S. F. de Boer, B. Buwalda and K. van Reenen, "Individual Variation in Coping with Stress: A Multi-Dimensional Approach of Ultimate and Proximate Mechanisms," Brain, Behavior and Evolution, Vol. 70, No. 4, 2007, pp. 218-226. doi:10.1159/000105485
[51] I. Gröticke, K. Hoffmann and W. Löscher, "Behavioral Alterations in the Pilocarpine Model of Temporal Lobe Epilepsy in Mice,” Experimental Neurology, Vol. 207, No. 2, 2007, pp. 329-349. doi:10.1016/j.expneurol.2007.06.021

[52] B. M. Spruijt, J. A. van Hooff and W. H. Gispen, ”Ethology and Neurobiology of Grooming Behaviour," Physiological Reviews, Vol. 72, No. 3, 1992, pp. 825-852. 